\title{
Virtual Simulation of Electric Bus Fleets for City Bus Transport Electrification Planning
}

\author{
Jakov Topić * , Jure Soldo, Filip Maletić, Branimir Škugor and Joško Deur \\ Faculty of Mechanical Engineering and Naval Architecture, University of Zagreb, 10002 Zagreb, Croatia; \\ jsoldo@fsb.hr (J.S.); fmaletic@fsb.hr (F.M.); bskugor@fsb.hr (B.Š.); jdeur@fsb.hr (J.D.) \\ * Correspondence: jtopic@fsb.hr; Tel.: +385-1-6168-555
}

Received: 20 May 2020; Accepted: 26 June 2020; Published: 2 July 2020

\begin{abstract}
City bus transport electrification has a strong potential of improving city air quality, reducing noise pollution and increasing passenger satisfaction. Since the city bus operation is rather deterministic and intermittent, the driving range- and charging-related concerns may be effectively overcome by means of fast charging at end stations and/or slow charging in depot. In order to support decision making processes, a simulation tool for planning of city bus transport electrification has been developed and it is presented in this paper. The tool is designed to use real/recorded driving cycles and techno-economic data, in order to calculate the optimal type and number of e-buses and chargers, and predict the total cost of ownership including investment and exploitation cost. The paper focuses on computationally efficient e-bus fleet simulation including powertrain control and charging management aspects, which is illustrated through main results of a pilot study of bus transport electrification planning for the city of Dubrovnik.
\end{abstract}

Keywords: city bus transport; electric vehicles; electrification; software tool; planning; control; charging management; simulation; analysis

\section{Introduction}

Due to environmental concerns, there is a strong tendency of electrifying road transport systems by means of introducing different types of electric vehicles [1]. Apart from reducing pollutant and $\mathrm{CO}_{2}$ emissions, electric vehicles (EV) are characterised by substantially reduced noise pollution, lower operating cost (including energy and maintenance cost) and generally better driving characteristics. On the other hand, higher investment cost, slow battery charging and limited driving range inhibit their faster proliferation [2]. This is why the transition to fully electric vehicles (FEV or $\mathrm{BEV}$ ) is characterised by application of hybrid electric vehicles (HEV) and plug-in hybrid electric vehicles (PHEV) [3].

City bus transport is a natural candidate for electrification, aiming at improvement in city air quality and reduction of noise. Since the city bus routes are known in advance and the operation is intermittent, the range- and charging-related issues are of lesser significance than with passenger cars. These issues can be tackled by the following two basic approaches [4]: (i) the buses are equipped with large enough battery packs to sustain half a day or even full day of operation, and the buses are efficiently recharged by using slow charging (typically overnight); and (ii) the battery size is minimised and superfast charging is employed at bus stops (typically end stations). Therefore, it is generally of interest to find optimal locations of charging stations, as considered in [5-11] with a focus on passenger cars and urban areas.

In [12], e-buses and corresponding charging systems are analysed from the total cost perspective by using data related to route specifications, timetables and other local conditions. Additionally, the authors have developed a user-friendly tool which enables the user to investigate and quantify 
trade-offs between EV battery size, charging infrastructure cost and vehicle fleet operational costs. However, all routes are modelled as straight lines between the bus stops and elevation is collected only at stops, thus hiding some relevant topographical features along the routes and affecting the analysis accuracy. In [13], a stochastic integer program was developed to jointly optimise charging station locations and bus fleet size, while considering stochastic bus charging demand and time-of-use electricity tariffs for the case of real-world network in Melbourne. However, this study does not consider charging scheduling for individual buses. The aforementioned city bus transport optimisation study [4] relies on an artificial urban bus driving cycle when conducting bus fleet simulations, thus neglecting influential effects of city traffic congestion, road slopes, often stops and so on. The authors of [14] indicated that lowering the fuel cost for electric buses can balance the high investment costs related to building charging infrastructure, while additionally achieving a significant reduction in pollutant emissions. To that extent, detailed techno-economic analyses comparing the total cost of ownership (TCO) of conventional and EV fleets should be conducted [15].

To the best of the authors' knowledge, studies dealing with extensive virtual simulations of different e-bus-type fleets based on real-life driving cycles and concerning spatially-distributed charging management and related TCO analyses have not been considered in the literature thus far. To fill the gap, a unique simulation tool for planning of city bus transport electrification, which contains all of the above functionalities, has been developed, which is described in this paper, including its application to a pilot study for the City of Dubrovnik. The tool consists of four modules aimed at (i) post-processing and statistical analysis of a large set of recorded driving cycles, (ii) simulation of conventional (CONV) and different types of e-buses (HEV, PHEV and BEV), (iii) virtual simulation of e-bus fleets over recorded driving cycles including user-defined setting of charging station locations and charging management itself and (iv) techno-economic analyses. The main contributions of the paper include: (i) creating a unique and flexible/transferable simulation tool resulting in realistic, data-driven transport electrification analyses; (ii) building a static map-based form of HEV/PHEV-type bus model including its control strategy, which drastically boost computational efficiency of large-scale fleet simulations; (iii) performing a detailed techno-economic analysis based on realistic virtual bus fleet simulation and actual technical data provided by city bus transport companies.

The paper is organised as follows. Section 2 describes the methodology of recording driving cycle data and overviews the structure of developed simulation tool. Section 3 outlines the Data Post-Processing Module (DPPM) and presents corresponding results of conventional city-bus transport system characterisation. Section 4 deals with E-Bus Simulation Module (EBSM) and discusses belonging simulation results for the four considered types of city buses. Section 5 describes the Charging Optimisation Module (COM) and overviews the results related to obtaining near-optimal charging infrastructure configuration for the cases of PHEV- and BEV-type bus fleets. The Techno-Economic Analysis Module (TEAM) is briefly described in Section 6, and the corresponding TCO results are discussed for various e-bus fleet scenarios. Concluding remarks are given in Section 7.

\section{Pilot Data and Simulation Tool Structure}

\subsection{Recording of Driving Cycle Data}

The driving cycle data have been collected on a sub-fleet of 10 MAN Lyon's City NL323 buses operating in the city of Dubrovnik. They are considered a good representative of the overall fleet, as they cover all major bus routes (Figure 1 ) and represent around $1 / 3$ of regularly used city buses. The driving data recording was performed by utilising a commercial GPS/GPRS vehicle tracking device installed in the selected buses for the purpose of this study. The data, collected from a built-in GPS device and vehicle CAN bus, are summarised in Table 1. Recording was conducted continuously for a period of five months, and the data sampling time was 1 second. 


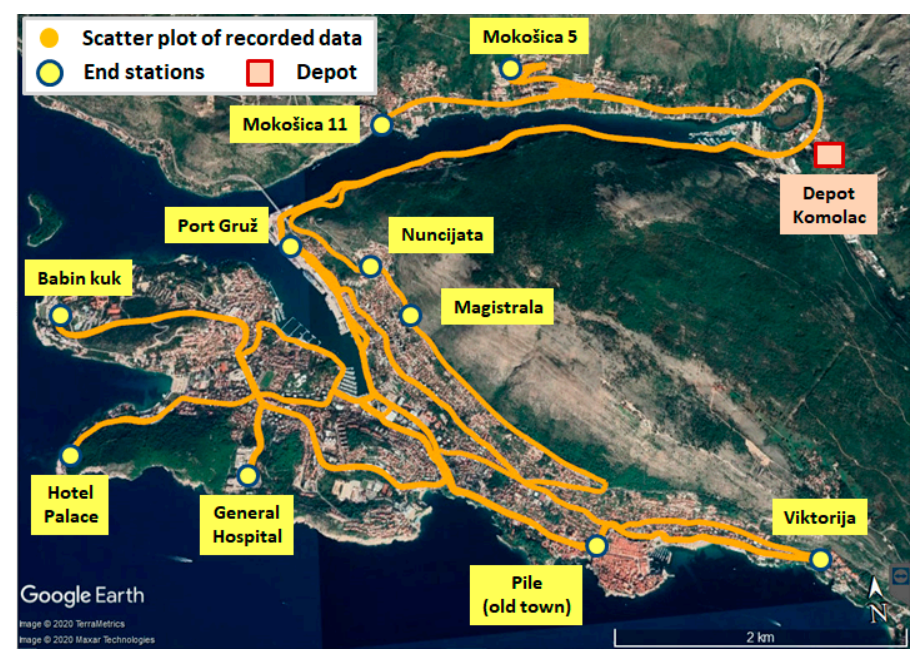

Figure 1. City bus routes in Dubrovnik along with end-station and depot locations.

Table 1. List of available city bus tracking data.

\begin{tabular}{lc}
\hline \multicolumn{1}{c}{ Measured Data } & Resolution \\
\hline GPS coordinates (latitude, longitude), $\left(^{\circ}\right)$ & $1.0 \times 10^{-7}$ \\
\hline Elevation height (altitude), $(\mathrm{m})$ & 0.1 \\
\hline Vehicle speed, $(\mathrm{km} / \mathrm{h})$ & 0.1 \\
\hline Travelled distance (from odometer), $(\mathrm{km})$ & 1.0 \\
\hline Accelerator pedal position, $(\%)$ & 1.0 \\
\hline Cumulative fuel consumption, $(\mathrm{L})$ & 0.5 \\
\hline Fuel level in reservoir, $(\%)$ & 1.0 \\
\hline Engine speed, $(\mathrm{rpm})$ & 1.0 \\
\hline Engine load, $(\%)$ & 1.0 \\
\hline
\end{tabular}

\subsection{Organisational Structure of Simulation Tool}

Figure 2 illustrates the structure of the developed tool, including the connections between the main modules. The tool is driven by recorded driving cycle data, and as the main output, it delivers the TCO over the projected fleet operational period (12 years, herein). The DPPM transforms the recorded driving data into individual driving cycles, and it also calculates various statistical features characterising the conventional city bus transport behaviours. The EBSM provides computer simulations of different types of city buses (CONV, HEV, PHEV, BEV) over the driving cycles extracted by the DPPM. The module outputs include the individual bus energy consumption (fuel and/or electricity) and various features of powertrain response (e.g., engine/e-motor operating points, gear ratio trajectories, etc.). The COM utilises the outputs of DPPM and EBSM to simulate the overall city bus fleet over the recorded driving cycles and optimise the PHEV- and BEV-type bus charging configuration and management. This module provides the number, location and type of chargers, the bus battery capacity and the number of reserve buses in the BEV case, which are required to fulfil the driving routes with sufficient battery charge. The COM also outputs the total fuel and/or electricity consumption over the considered period of operation. The TEAM uses the output data from the COM module, as well as the data on bus transport investment and exploitation/maintenance cost, in order to calculate the TCO. 


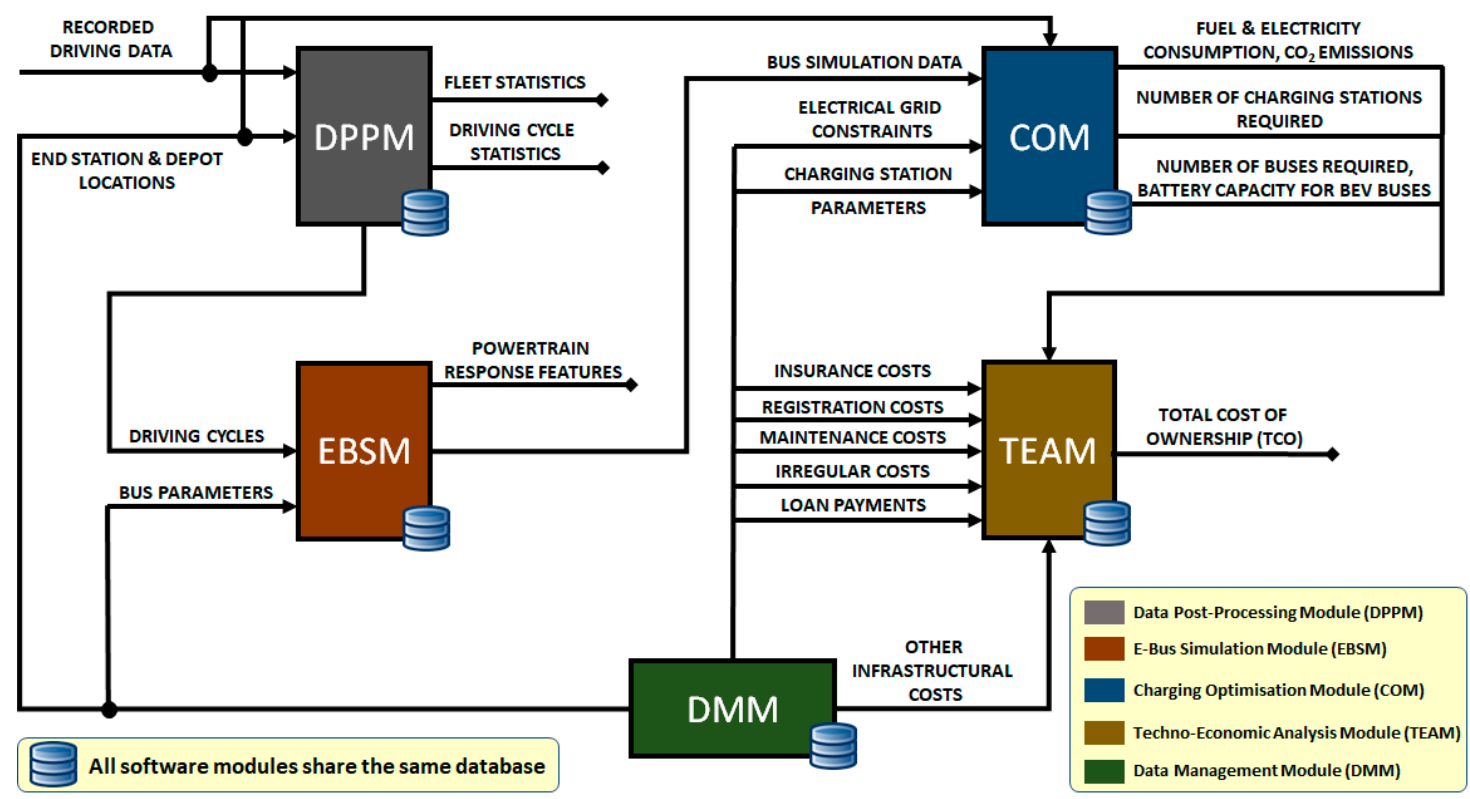

Figure 2. Organisational structure of simulation tool.

The simulation tool is written in Python object-oriented programming language, with computationally demanded routines coded in $C$ language. The Python language has been selected because it is available in open-source domain, it supports multiple platforms, has a vast number of available libraries, and is dynamically typed language (i.e., does not require declaring of data type of a variable) convenient for rapid prototyping. The simulation tool is designed in a user-friendly way (based on a graphical user interface (GUI) including windows, tabs, I/O data interfaces, etc.) and has in mind the transferability to other cities using a common/shared database. The database serves as a main storage for recorded driving cycle data, and plays the role of an intermediary between the main tool modules. In addition, the simulation tool includes the Data Management Module (DMM), which provides greater flexibility and adaptability to different cities' transport system configurations. DMM enables the user to define all static data (system parameters) required by the simulation tool, e.g., those related to vehicle model parameters, end-station and depot locations, charging station parameters and techno-economic data.

\section{Data Post-Processing Module (DPPM)}

\subsection{General Description}

According to the DPPM flowchart shown in Figure 3, the recorded driving data are first processed and stored in a database. Next, the driving cycles are extracted by using the DMM-based data related to geographical coordinates of end stations and depot (Section 3.2). At the same time, the fleet statistics are calculated for the entire fleet and individual buses (Section 3.3). Finally, the module outputs including driving cycles and statistical features can be plotted in different formats, and they are saved into the database.

\subsection{Extraction of Driving Cycles}

A single driving cycle is defined by the velocity vs. time and road slope vs. travelled distance profiles between two consecutive end stations, including depot (see Figure 1). The corresponding time profiles of cumulative fuel consumption are also extracted. 
INPUTS

DATA PROCESSING

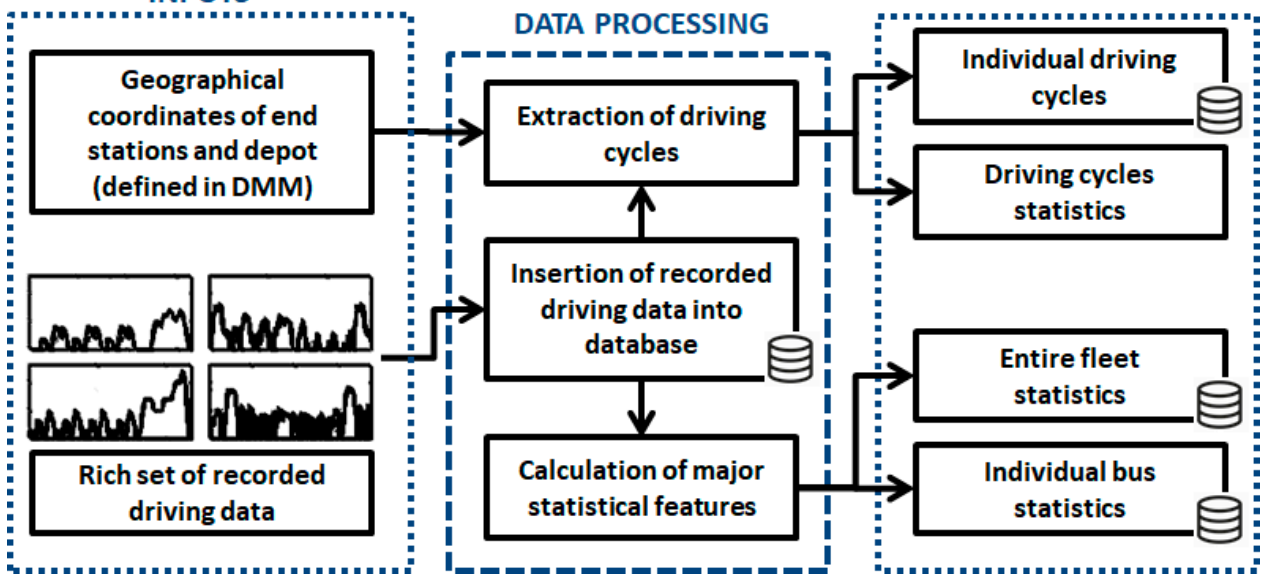

Figure 3. Flowchart of Data Post-Processing Module (DPPM).

The driving cycle segmentation process resulted in a total of 122,727 extracted driving cycles. An example of recorded driving cycle is shown in Figure 4. Note that the vehicle velocity is directly measured, while the road grade is reconstructed from the rate of change of altitude when expressed with respect to the travelled distance. In order to reduce the noise in the reconstructed road slope profile, the altitude signal is pre-filtered by a low-pass double-sided Butterworth filter [16].
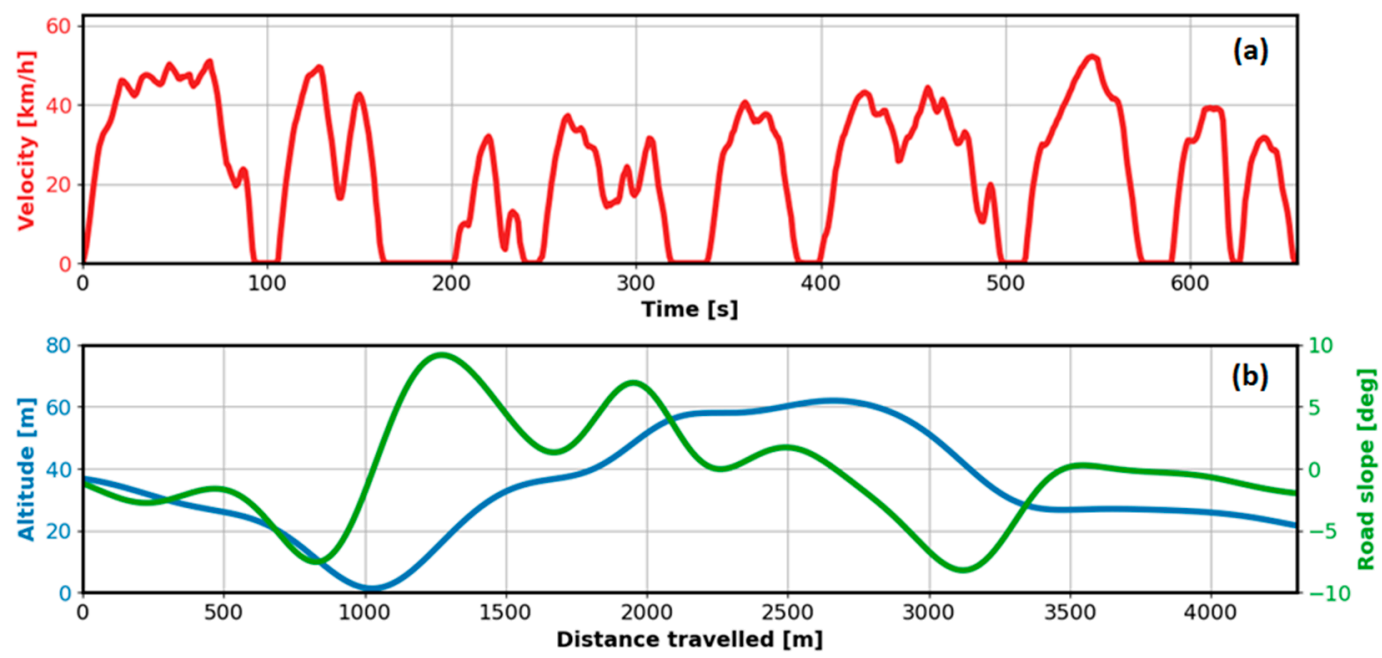

Figure 4. Sample of reconstructed driving cycle for city bus route Hotel Palace-Pile and afternoon hours: velocity vs. time profile (a) and road slope vs. distance travelled given along altitude source profile (b).

\subsection{Calculation of Vehicle Fleet Statistics}

A rich set of statistically significant driving features is calculated for the purpose of actual/conventional city-bus transport system characterisation and in support of transport electrification (e.g., locating charging stations, Section 5). The features related to individual buses, all given per-day-basis, include: the total fuel consumption and distance travelled; average fuel consumption in $\mathrm{L} / 100 \mathrm{~km}$; the total time the bus is dwelling at depot, individual end stations or any other locations (typically bus stops); total driving time; mean velocity; number of bus stops per kilometre; number of bus visits to depot and end stations. The results are stored in a two-dimensional (2D) matrix (one per bus), whose rows and columns represent individual days and the statistical features, respectively.

Once the individual statistics are stored, they are further used to calculate the same features for the entire fleet on the basis of individual day, week, month or year. The results can be presented in 
different ways, e.g., instead of individual dwelling times, one can get the information about percentage share of time the buses or entire fleet are resting at depot, end stations and other locations (see Figure 5). Specific fleet features requiring denser sampling (30 min, herein) are also calculated. An example of the daily average fleet velocity profile is shown in Figure 6. Other features related to entire fleet include: average number of buses being parked at depot on 24-hour time basis (Figure 6), clusters of buses parking durations in relation to geographical coordinates, count of transitions between individual end stations/depot, etc.

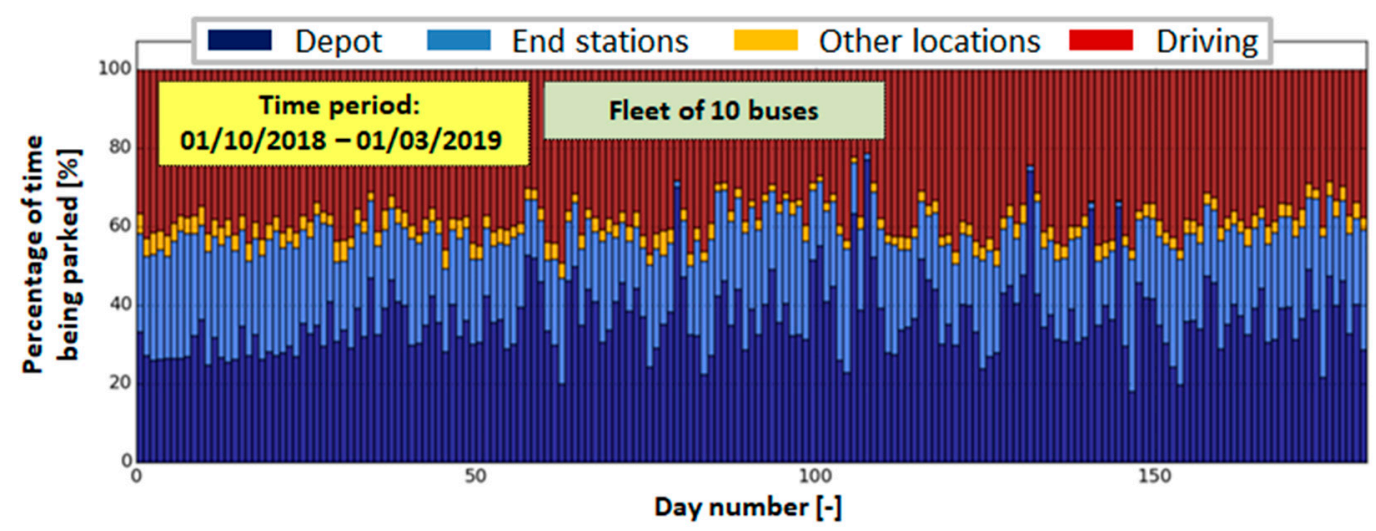

Figure 5. Percentage time share of buses being operated and parked in depot, end stations and other locations.

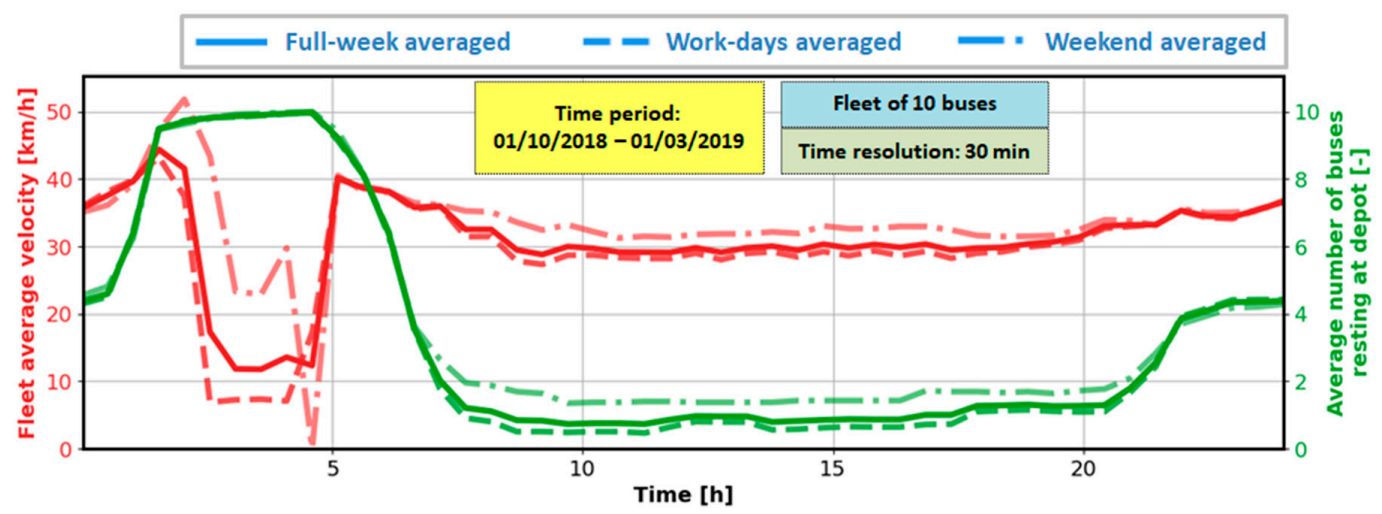

Figure 6. Time profiles of fleet average velocity and average number of buses resting at the depot, both given on daily basis and averaged over the considered five-month period.

Figure 6 indicates that the average bus velocity when operating is around $30 \mathrm{~km} / \mathrm{h}$ and it is higher in early morning and night hours, as well as over weekends. The low-velocity gap between 2 a.m. and 5 a.m. corresponds to the interval when most of the buses are parked in the depot. The buses rarely visit the depot in other time intervals, particularly over the work days (when the average number of buses is lower than 1 ).

Figure 5 confirms that the share of total time of buses being parked in the depot is relatively small (approx. 30\%) and comparable to the share of end-station parking time (approx. 25\%). The rest of the time the buses spend in driving (40\%), while only for a small portion of time (approx. $5 \%$ ), they rest elsewhere, typically at bus stops.

Figure $7 \mathrm{a}$ indicates that there are significant differences in bus resting time at different end stations. The average resting durations for most pronounced end stations are between 10 and $20 \mathrm{~min}$, thus making them good candidates for installation of fast chargers. When selecting the best candidates, a charging station utilisation factor should also be considered (Figure $7 \mathrm{~b}$ ). The final end stations targeted 
for electrification are then obtained by taking the cross-section of these two criteria (end stations underlined in red in Figure 7).
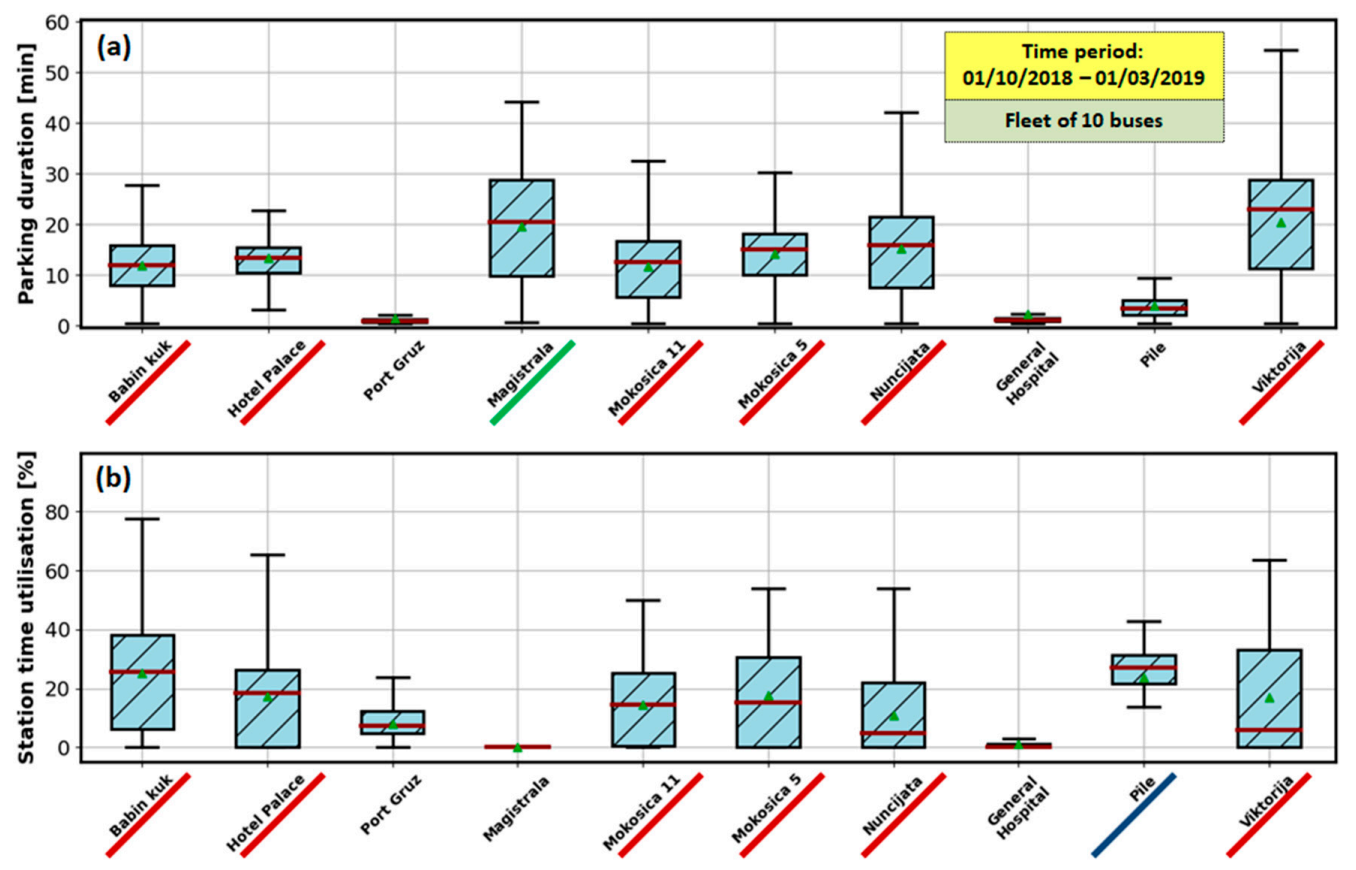

Figure 7. Boxplots of time duration of buses being parked at different end stations (a) and end stations charging utilisation $(\mathbf{b})$.

\section{E-Bus Simulation Module (EBSM)}

\subsection{General Description}

As illustrated in flowchart in Figure 8, the EBSM simulates different types of city buses (CONV, HEV, PHEV and BEV) over the recorded driving cycles extracted by the DPPM (Section 3). The simulation first involves loading of vehicle-related parameters from the database, which need to be previously defined in the DMM. Next, the vehicle is simulated over the selected driving cycles by using the numerically-efficient backward-looking model (Section 4.2). Note that the vehicle model includes a control strategy that manages the gear ratio in the CONV and BEV cases, and the internal combustion engine (ICE) torque in the HEV and PHEV cases (Section 4.3). The emphasis has been on transforming the previously developed control strategy $[17,18]$ to a form of off-line optimised maps, instead of using an on-line optimisation algorithm. The EBSM outputs time responses of key powertrain variables, such as cumulative fuel and electricity consumption, $\mathrm{CO}_{2}$ emissions and transmission gear ratio.

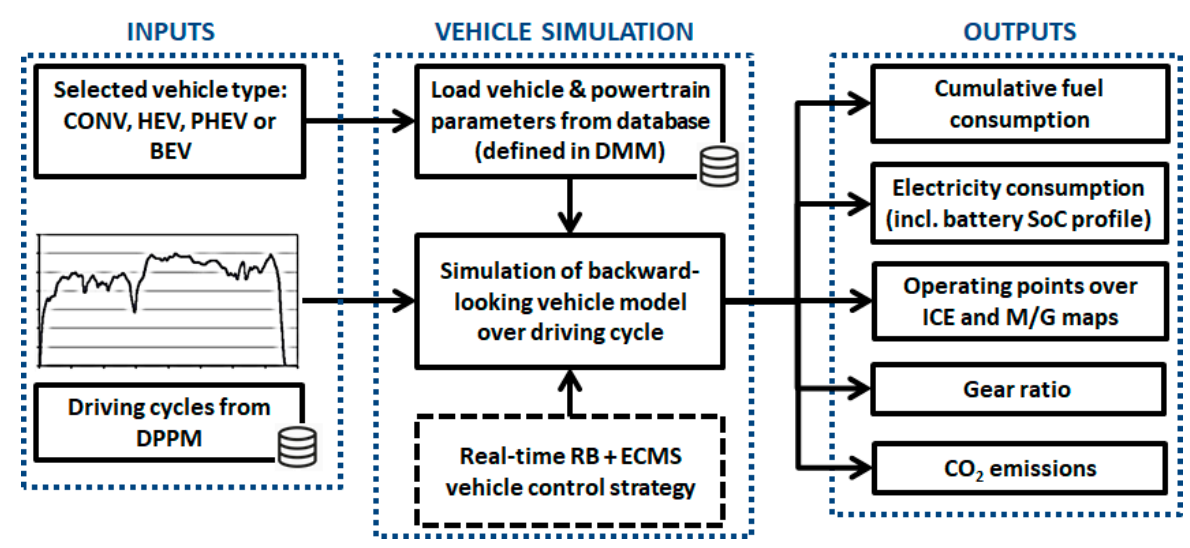

Figure 8. Flowchart of E-Bus Simulation Module (EBSM). 


\subsection{Vehicle Modelling}

\subsubsection{Considered City Buses}

The MAN Lion's City buses with the length of $12 \mathrm{~m}$ and the capacity of up to 126 passengers are represented in virtual simulation by the Volvo 7900 bus model. The Volvo 7900 platform was chosen because it includes all three e-bus variants considered (HEV, PHEV and BEV; Table 2).

Table 2. Basic parameters of modelled $12 \mathrm{~m}$ city buses [19].

\begin{tabular}{|c|c|c|c|c|}
\hline Parameter & CONV & HEV & PHEV & BEV \\
\hline Model label & $\begin{array}{l}\text { Volvo } 7900 \\
\text { (Diesel) }\end{array}$ & Volvo 7900 Hybrid & Volvo 7900 Electric Hybrid & Volvo 7900 Electric \\
\hline Maximum ICE power & $228 \mathrm{~kW}$ & $161 \mathrm{~kW}$ & $173 \mathrm{~kW}$ & N/A \\
\hline Maximum e-motor power & N/A & $120 \mathrm{~kW}$ & $150 \mathrm{~kW}$ & $160 \mathrm{~kW}$ \\
\hline Battery capacity & N/A & $4.8 \mathrm{kWh}$ & $19 \mathrm{kWh}$ & $76 \mathrm{kWh}$ \\
\hline Transmission model (type) & $\begin{array}{l}\text { ZF 6AP 400B } \\
\text { (AT) }\end{array}$ & \multicolumn{2}{|c|}{$\begin{array}{c}\text { Volvo AT2412 I-Shift } \\
\text { (AMT) }\end{array}$} & $\begin{array}{l}\text { Volvo 2-speed } \\
\quad \text { (AMT) }\end{array}$ \\
\hline Number of gears & 6 & \multicolumn{2}{|r|}{12} & 2 \\
\hline $\begin{array}{l}\text { Maximum fast charging } \\
\text { power }\end{array}$ & N/A & $\mathrm{N} / \mathrm{A}$ & $150 \mathrm{~kW}$ & $300 \mathrm{~kW}$ \\
\hline
\end{tabular}

Volvo e-buses use lithium iron phosphate (LFP) battery due to its high specific power required for propulsion and fast charging. The battery packs of Volvo $7900 \mathrm{HEV}$, PHEV and BEV bus variants have energy capacities of $4.8 \mathrm{kWh}, 19 \mathrm{kWh}$ and $76 \mathrm{kWh}$, respectively (Table 2).

\subsubsection{Modelling}

In the backward-looking models, the powertrain variables are calculated in the direction from the wheels towards the engine and/or e-motor, starting from the wheel speed and torque being defined by the driving cycles [20]. In order to boost the computational efficiency, the powertrain dynamics is neglected, except for the battery state-of-charge $(\mathrm{SoC})$ dynamics that are represented by a first-order model.

The considered parallel configuration of a HEV/PHEV-type bus is illustrated in Figure 9a [17]. The battery is represented by the equivalent battery circuit model shown in Figure $9 b$, which is described by the following state equation $[20,21]$ :

$$
S o C(t)=-\frac{I_{\text {batt }}(t)}{Q_{\max }}=\frac{\sqrt{U_{o c}^{2}(S o C)-4 R(S o C) P_{b a t t}(t)}-U_{o c}(S o C)}{2 Q_{\max } R(S o C)},
$$

where $U_{o c}$ is the open-circuit voltage, $R$ is the internal resistance, $I_{b a t t}$ is the battery current, $Q_{\max }$ is the maximal battery charge capacity and the SoC is defined as $S o C=Q / Q_{\max }$, with $Q$ denoting the actual charge.

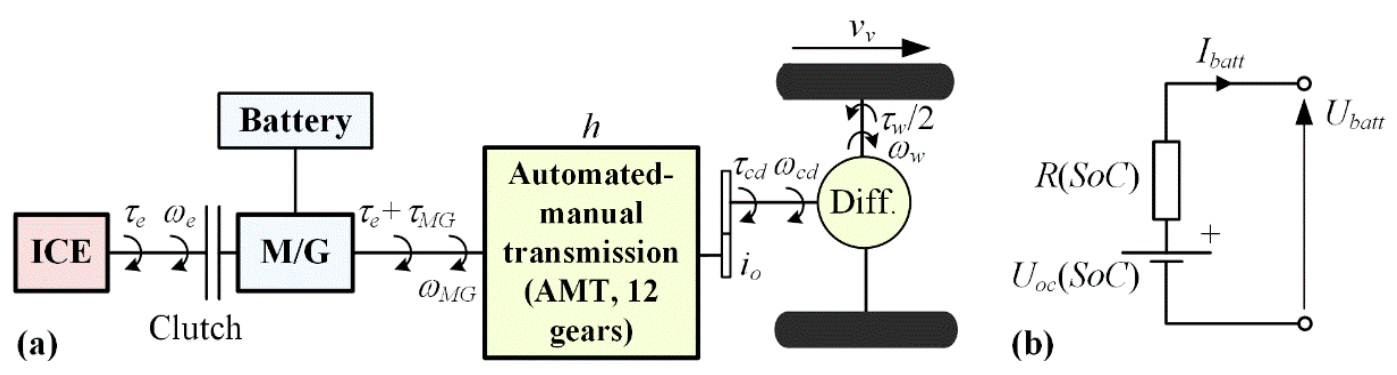

Figure 9. Functional scheme of considered parallel HEV/PHEV powertrain (a) and battery equivalent circuit model (b). 
The model input $P_{\text {batt }}$ represents the battery output power defined as:

$$
P_{b a t t}=\eta_{M G}^{k} \cdot \tau_{M G} \cdot \omega_{M G},
$$

where $\tau_{M G}$ and $\omega_{M G}$ are the motor/generator (M/G) torque and speed, respectively, $\eta_{M G}$ is the $\mathrm{M} / \mathrm{G}$ machine efficiency (represented by $\eta_{M G}\left(\omega_{M G}, \tau_{M G}\right)$ map; see Figure 10c and [17]) and the coefficient $k$ is equal to 1 or -1 depending on whether the $\mathrm{M} / \mathrm{G}$ machine operates as a generator or motor, respectively. The $\mathrm{M} / \mathrm{G}$ machine speed and torque are given by the following kinematic equations:

$$
\begin{gathered}
\omega_{M G}=i_{0} h \omega_{w}=i_{0} h \frac{v_{v}}{r_{w}}, \\
\tau_{M G}=\frac{\frac{\tau_{w}}{\eta_{t r}\left(\tau_{w}\right)}+\frac{P_{0}\left(\omega_{w}\right)}{\omega_{w}}}{i_{0} h}-\tau_{e},
\end{gathered}
$$

where $v_{v}$ is the vehicle velocity, $r_{w}$ is the tire effective radius, $h$ and $i_{0}$ are the transmission and final drive ratios, respectively, $\tau_{w}$ and $w_{w}$ are the total wheels torque and speed, respectively, $\eta_{t r}\left(\tau_{w}\right)$ and $P_{0}\left(\omega_{w}\right)$ are drivetrain efficiency and idle power loss maps [17] and $\tau_{e}$ is the engine torque considered as a control variable (in addition to $h$ ). The wheel torque is determined according to vehicle longitudinal dynamics equation covering the vehicle acceleration torque and aerodynamic, road grade and rolling resistances [20].
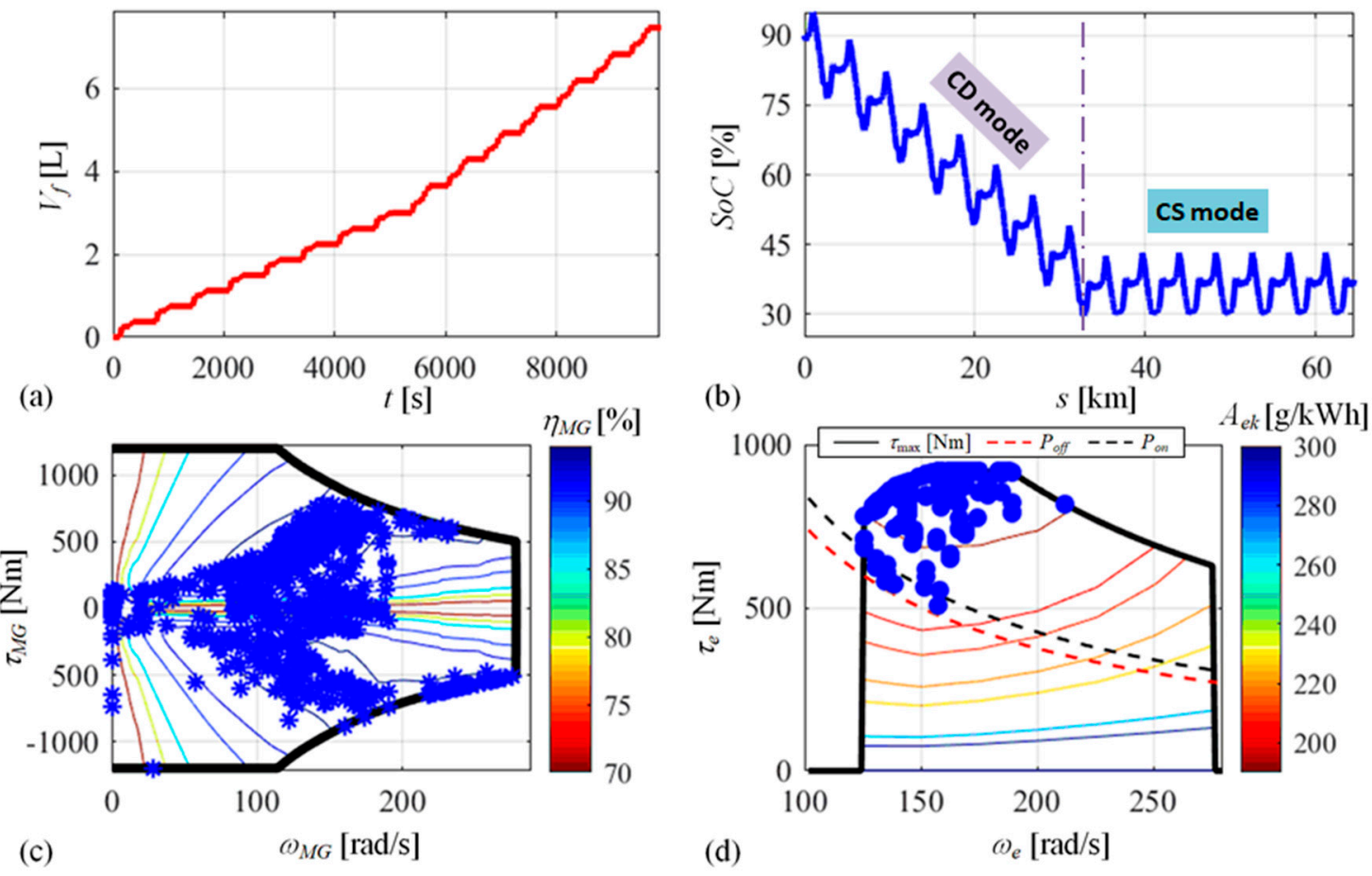

Figure 10. Simulation results for PHEV bus over the driving cycle given in Figure 4 repeated 15 times, including: cumulative fuel consumption time response (a), battery SoC vs. distance travelled (b), $\mathrm{M} / \mathrm{G}$ machine operating points (c), and engine operating points (d).

The fuel consumption at the driving cycle end time $t_{f}$ is determined as:

$$
V_{f}=\frac{1}{\rho_{\text {fuel }}} \int_{0}^{t_{f}} \dot{m}_{f} d t=\frac{1}{\rho_{\text {fuel }}} \int_{0}^{t_{f}}\left(A_{e k}\left(\tau_{e}, \omega_{e}\right) \frac{\tau_{e} \omega_{e}}{3.6 \cdot 10^{6}}\right) d t,
$$

where $A_{e k}$ is the engine specific fuel consumption given by the map shown in Figure 11, $\rho_{f u e l}$ is the diesel fuel density ( $\rho_{f u e l}=845 \mathrm{~g} / \mathrm{L}$ ) and $\omega_{e}$ equals $\omega_{M G}$ or 0 when the engine is switched on or off, 
respectively. Note that the integral Equation (5) is realised by using the Euler integration method with the common sample time of the backward model equal to $1 \mathrm{~s}$.

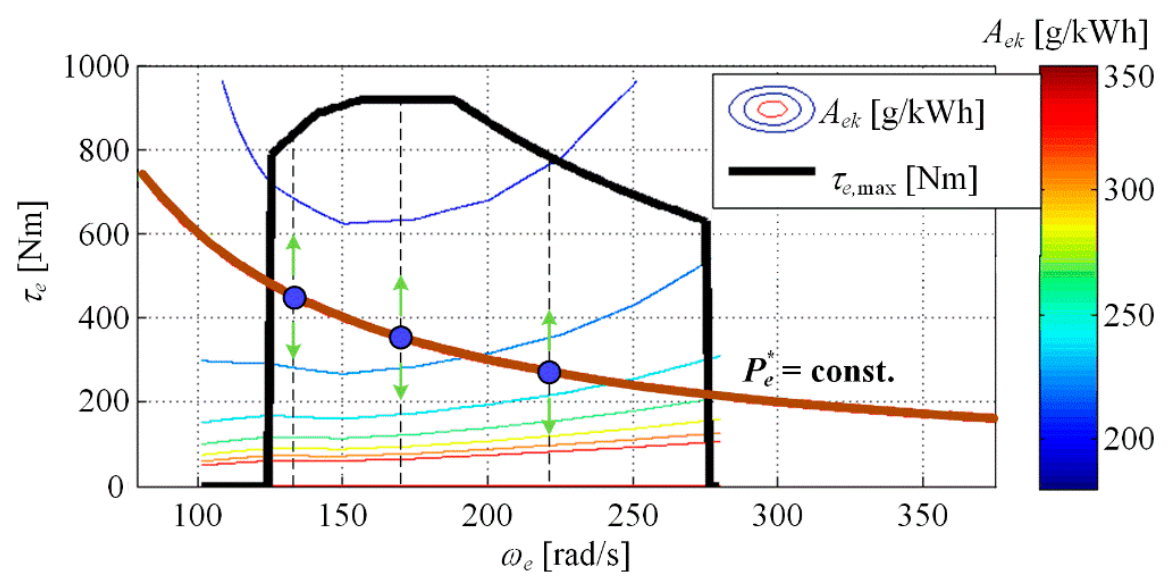

Figure 11. Engine specific fuel consumption map including illustration of ECMS-based operating point search.

In the case of a conventional (CONV) bus, the battery and $\mathrm{M} / \mathrm{G}$ machine are omitted from the functional scheme in Figure 9, while the AMT is replaced by a torque converter AT. The torque converter is represented by a backward-looking map $\omega_{l}\left(\omega_{t}, \tau_{t}\right)$ derived offline from the well-known static torque converter model (see [22] and references therein) and the map $\tau_{i}=\tau_{t} / R_{\tau}\left(\omega_{t} / \omega_{i}\right)$, where the subscripts $i$ and $t$ denote impeller/engine and turbine/transmission input variables, and $R_{\tau}($.$) is the static model$ torque ratio map. For the BEV-type bus, the engine is omitted and a two-speed AMT is used.

Vehicle auxiliary devices (HVAC system, servo steering, air compressor, engine cooling fan and alternator) are modelled based on the nominal power of each device and a binary power-modulating signal, whose duty cycle is made dependent on the driving and atmospheric conditions (urban driving conditions and ambient temperature dependence are assumed) [23].

\subsection{Control Strategy}

In the BEV case, the aim of control strategy is to find an optimal gear ratio $h^{*}$ in each sampling instant, which minimises the battery discharging power and maximises the battery recharging/ regenerative power:

$$
h^{*}=\underset{h}{\operatorname{argmin}}\left\{\begin{array}{l}
\eta_{b a t t}^{k} P_{b a t t}\left(P_{d}, \omega_{w}, h\right), \quad \text { for } P_{b a t t}<0 \text { (charging) } \\
\eta_{\text {batt }}^{k} P_{\text {batt }}\left(P_{d}, \omega_{w}, h\right), \quad \text { for } P_{\text {batt }} \geq 0 \text { (discharging) }
\end{array},\right.
$$

where $\eta_{b a t t}$ is the battery efficiency and $P_{d}$ is the transmission input power demand calculated from $v_{v}$ and $\tau_{w}$ as shown in Figure 12. The optimal gear ratio $h^{*}$ is calculated offline and mapped as $h^{*}\left(P_{d}, \omega_{w}\right)$. The SoC dependence of $P_{\text {batt }}$ has a minor effect on $h^{*}$ and is neglected in Equation (6), and further on.

Similarly, in the CONV case, the control strategy finds an optimal gear ratio $h^{*}$ that minimises the fuel mass flow $\dot{m}_{f}$ :

$$
h^{*}=\underset{h}{\operatorname{argmin}} \dot{m}_{f}\left(P_{d}, \omega_{w}, h\right) .
$$

The off-line obtained optimal solutions are mapped as $h^{*}\left(P_{d}, \omega_{w}\right)$. 


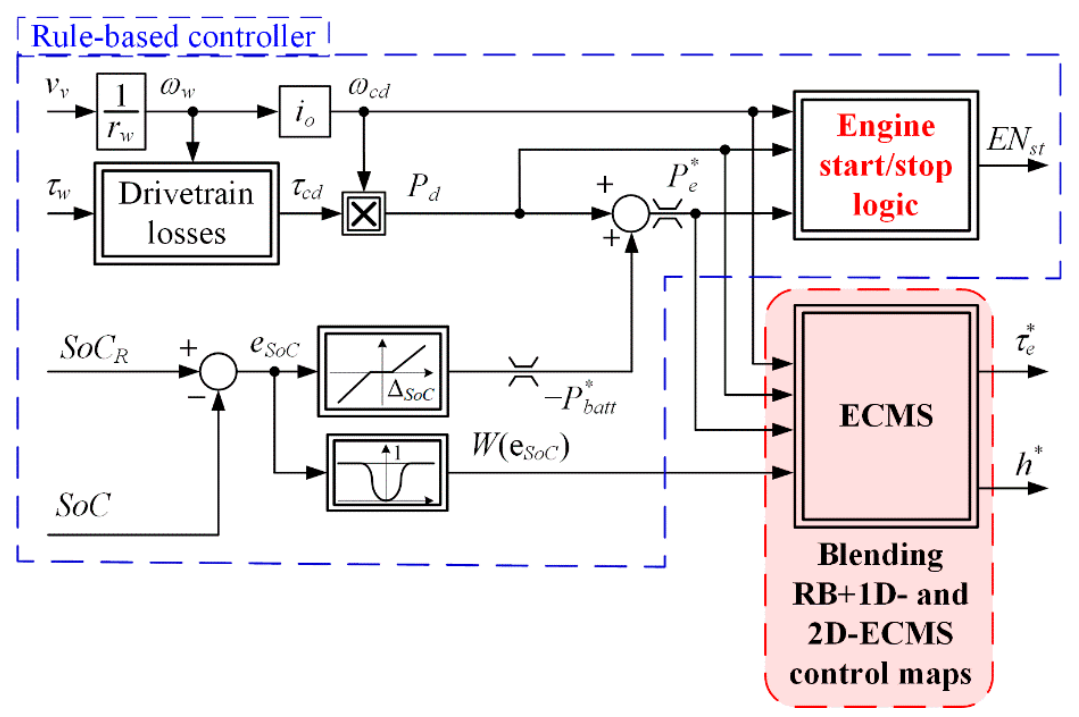

Figure 12. Block diagram map-based RB+ECMS control strategy.

The HEV and PHEV control strategy determines the transmission gear ratio $h$ and the engine torque $\tau_{e}$ based on combining a rule-based (RB) controller and an equivalent consumption minimisation strategy (ECMS) $[17,24]$. The original RB+ECMS strategy is modified here to allow for computationally-efficient map-based realization, which is shown in Figure 12. A proportional-like battery SoC controller commands the battery recharging power- $P_{\text {batt }}$, which is added to the transmission input power demand $P_{d}$ to obtain the engine power demand $P_{e}^{*}$. The demanded engine power $P^{*}{ }_{e}$ is compared with engine on and off thresholds $P_{\text {on }}$ and $P_{\text {off }}<P_{\text {on }}$, respectively, in order to determine the engine on/off state $E N_{s t}$. The engine is exceptionally kept switched on in the case $P_{e}^{*}$ $<P_{\text {off }}$ when the speed-dependent $\mathrm{M} / \mathrm{G}$ machine power limit is not high enough to satisfy the driver power demand $P_{d}$ in the fully electric driving mode. If the engine is switched on, the signal $P^{*}{ }_{e}$ is fed to the ECMS to find the optimal values of $h$ and $\tau_{e}$. Otherwise, the electric driving mode is activated and the gear ratio is determined according to Equation (6).

In the original RB+ECMS strategy [17], the equivalent fuel consumption $\dot{m}_{e q}\left(P_{e}, P_{d}, \omega_{w}, h, S o C\right)$ is minimised instantaneously and on-line with respect to both control variables $h$ and $\tau_{e}$. In the simplified map-based RB+ECMS version considered here, the equivalent fuel consumption is minimised in two stages. In the first stage, the ECMS is applied to discrete operating points along the constant power curve $P_{e}^{*}$ (denoted in Figure 11 by blue circles) to determine the optimal gear ratio:

$$
h^{*}=\underset{h}{\operatorname{argmin}} \dot{m}_{e q}\left(P_{e}^{*}, P_{d}, \omega_{w}, h\right),
$$

where $\dot{m}_{e q}$ is the equivalent fuel consumption rate containing the actual fuel consumption rate $\dot{m}_{f}$ and a battery power-equivalent fuel rate (see $[17,24]$ for details). The off-line obtained optimal solutions are stored in a three-dimensional (3D) map $h^{*}\left(P^{*}{ }_{e}, P_{d}, \omega_{w}\right)$ representing the RB+1D-ECMS control map. In the second stage, the ECMS is applied along the engine torque axis (see green arrows in Figure 11):

$$
\tau_{e, 2 D}^{*}=\underset{\tau_{e}}{\operatorname{argmin}} \dot{m}_{e q}\left(P_{d}, \omega_{e}, \tau_{e}\right) \text {. }
$$

The off-line optimisation results are stored in a 2D map $\tau_{e, 2 D}^{*}\left(P_{d}, \omega_{e}\right)$ representing the 2D-ECMS control map. Finally, the engine torque obtained by the RB+1D-ECMS (as $\tau_{e, R B}^{*}=P^{*} e_{e} /\left(h^{*} i_{0} \omega_{w}\right)$ ) and the one obtained by the 2D-ECMS are combined/blended on-line using the SoC control error $\left(e_{S o C}\right)$-dependent weighting factor $W\left(e_{S o C}\right)[17,24]$ :

$$
\tau_{e}^{*}=\tau_{e, R B}^{*} W\left(e_{S O C}\right)+\tau_{e, 2 D}^{*}\left(1-W\left(e_{S o C}\right)\right),
$$


where $W($.$) is an SoC control error-dependent weighting function illustrated in Figure 12. For small$ SoC control errors, the 2D-ECMS is dominant, while for large SoC control errors, the RB+1D-ECMS is preferred to satisfy the engine power demand $P_{e}^{*}$ (and, thus, the battery power demand $P^{*}$ batt).

Finally, gear shift delay logic is implemented to prevent frequent gear switching [17]. The goal is to prevent gear shift occurrence in $k^{\text {th }}$ time step, i.e., rather use the gear ratio from the previous $(k-1)^{\text {th }}$ step, $h_{k-1}$, if the time elapsed since the last gear shift $t_{s h}$ is lower than an arbitrarily set shift delay threshold $t_{t h}$ and if $h_{k-1}$ gives feasible set $\mathbf{u}_{k}$ of engine and M/G machine operating points in the $k^{\text {th }}$ step (denoted by $\Pi$ ):

$$
h_{k}^{*}= \begin{cases}h_{k-1}^{*}{ }^{\prime} & \text { for } t_{s h}<t_{t h} \text { and } \mathbf{u}_{k}\left(P_{e}^{*}, P_{d, k}, \omega_{w, k}, h_{k-1}^{*}\right) \in \Pi \\ h^{*}\left(P_{e, k^{\prime}}^{*} P_{d, k}, \omega_{w, k}\right), & \text { otherwise }\end{cases}
$$

The same gear shifting delay logic is applied in the CONV and BEV cases. The shift delay threshold is set here to $t_{t h}=2 \mathrm{~s}$.

The above described simplified, map-based control strategy has been found to result in a negligible model response deviation when compared to the use of original strategy, which was proven to be close to the dynamic programming-based global optimum [17]. On the other hand, the execution time is reduced by around 200 times. The achieved execution time, expressed as the amount of microseconds needed to simulate one second of real time (for a workstation having 16 GB RAM and Intel ${ }^{\circledR}$ Xeon ${ }^{\circledR}$ Processor E5-1620 v3 @ 3.50GHz) falls in the range from 50 to $87 \mu \mathrm{s} / \mathrm{s}$ depending on vehicle type. This results in approximate yearly 10-bus fleet simulation time ranging from approximately $4.5 \mathrm{~h}$ to $7.5 \mathrm{~h}$, which is deemed acceptable for such a large-scale fleet simulation. Note that the execution time could further be reduced by using parallel computing.

The PHEV can operate in two characteristic modes [20]: (i) charge depleting (CD) followed by charge sustaining (CS), where the former involves the engine only when absolutely needed and the latter correspond to hybrid operation at the target SoC of 30\%; (ii) blended mode where engine is regularly used all over the driving cycle for additional energy savings. For the sake of simplicity, the $\mathrm{CD} / \mathrm{CS}$ mode is considered in this paper.

\subsection{Simulation Results}

The results related to relative fuel and/or electricity consumptions for different city bus types are given in Table 3 for the full recording period. The relative difference between the simulated (Sim) and recorded (Rec) fuel consumptions for the CONV bus is equal to only $1.4 \%$. Therefore, the CONV simulation model used as a basis for e-bus modelling can be considered accurate. Note that although the real and simulated buses are different (MAN Lion City and Volvo 7900), the validation is considered fair, as the two buses are rather comparable in terms of size, mass, engine power, number of passengers and other similar factors.

The simulated electricity consumptions of PHEV- and BEV-type buses are close to recorded ones documented in the ZeEUS project report [25] for Volvo 7900 bus series (Table 3). In the PHEV case, the simulated fuel consumption is by $30 \%$ higher than the ZeEUS recorded one, but this discrepancy is compensated for by $26 \%$ higher recorded electricity consumption when compared to the simulated one. In the BEV case, the relative difference in electricity consumption equals $6 \%$. The simulated HEV fuel consumption is reduced by $50 \%$ when compared to CONV simulation results, while the manufacturer states the fuel consumption reduction from $39 \%$ to $45 \%$ reported by operators [19]. The observed, relatively modest discrepancies in fuel/electricity consumption may be related to difference in considered bus weights (passenger weight is fixed to $1250 \mathrm{~kg}$ ), road slope and traffic congestion conditions, as well as regenerative braking capacity (set to the maximum amount of $100 \%$ in simulation). 
Table 3. Recorded and simulated relative fuel and electricity consumptions for different bus types and full recording period.

\begin{tabular}{|c|c|c|c|c|c|c|c|c|}
\hline & \multicolumn{2}{|c|}{ CONV } & \multicolumn{2}{|c|}{ HEV } & \multicolumn{2}{|c|}{ PHEV } & \multicolumn{2}{|c|}{ BEV } \\
\hline & $\operatorname{Rec} *$ & Sim & Est ** & Sim & $\operatorname{Rec} *$ & Sim & $\operatorname{Rec} *$ & Sim \\
\hline Fuel consumption, (L/100 km) & 42.9 & 43.5 & 24.8 & 21.6 & 10.2 & 13.3 & \multicolumn{2}{|c|}{ N/A } \\
\hline $\begin{array}{l}\text { Electricity consumption, } \\
(\mathrm{kWh} / 100 \mathrm{~km})\end{array}$ & \multicolumn{2}{|c|}{ N/A } & \multicolumn{2}{|c|}{ N/A } & 53 & 42.4 & 83 & 77.9 \\
\hline
\end{tabular}

Figure 10 shows the PHEV-case simulation results for the recorded driving cycle shown in Figure 4 repeated 15 times and the initial battery SoC equal to $90 \%$. When the CD mode is active, the engine is used only when needed and the cumulative fuel consumption is often constant (a stepwise-like response, Figure 10a). After entering the CS mode, the engine is more active to sustain the battery SoC (Figure 10b). The control strategy deploys the operating points of engine (when switched on) and $\mathrm{M} / \mathrm{G}$ machine in the high efficiency areas of corresponding maps (Figure 10c-d), thus minimising the energy consumption.

\section{Charging Optimisation Module (COM)}

\subsection{General Description}

A generic framework for virtual simulation of an e-bus fleet over the recorded driving cycles is represented by the flowchart shown in Figure 13. The model of city bus of any type (Section 4) is initialised based on the data stored in DMM and virtually run over the recorded driving cycles for the specified period of time, thus resulting in fuel and/or electricity consumption output data. In the case of a PHEV- or BEV-type bus the user needs to specify locations and types of charging stations, the nominal vehicle battery capacity and grid power constraints to execute the simulation. The simulation is repeatedly run for a peak day or peak week for different charging infrastructure and battery capacity specifications, in order to find a nearly-optimal configuration, which would be finally re-run for a given, longer period of time to calculate the fuel/electricity consumption and charging station utilisation statistics. In the case of BEV-type bus, the COM automatically adds reserve bus(es) if needed, and calculate their final number and related statistics. The bus intervening algorithm monitors each BEV's battery $\mathrm{SoC}$, and when it drops below a predefined minimum value $(0.3$, herein), the immediate replacement with reserve e-bus is conducted. At the same time, it is taken into account that the depleted bus needs some constant time to reach the nearest charging station, where it is to be charged (as any other bus), and once it is fully charged, it will be waiting for the next replacement/intervention.

\subsection{Charging Management Algorithm}

Charging management is described by the flowchart shown in Figure 14. First, it is checked if a PHEV- or BEV-type bus has arrived to an end station/depot and if that station has a charger installed. If the charger is not occupied or if the bus has a lower battery SoC of any of the buses already being charged, the bus is put on charge; otherwise, it remains in the charging queue. Note that each station can be set to have an arbitrary number of chargers, as described with Figure 13. 


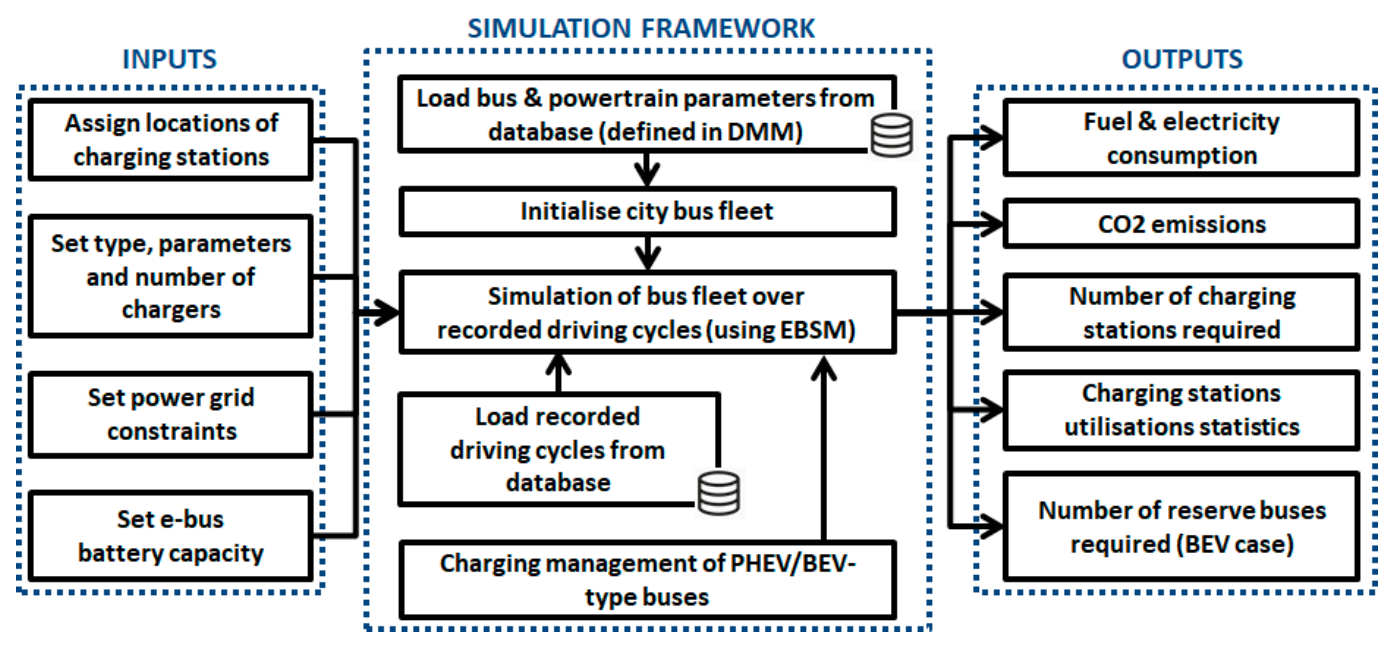

Figure 13. Flowchart of Charging Optimisation Module (COM) with embedded EBSM functionality.

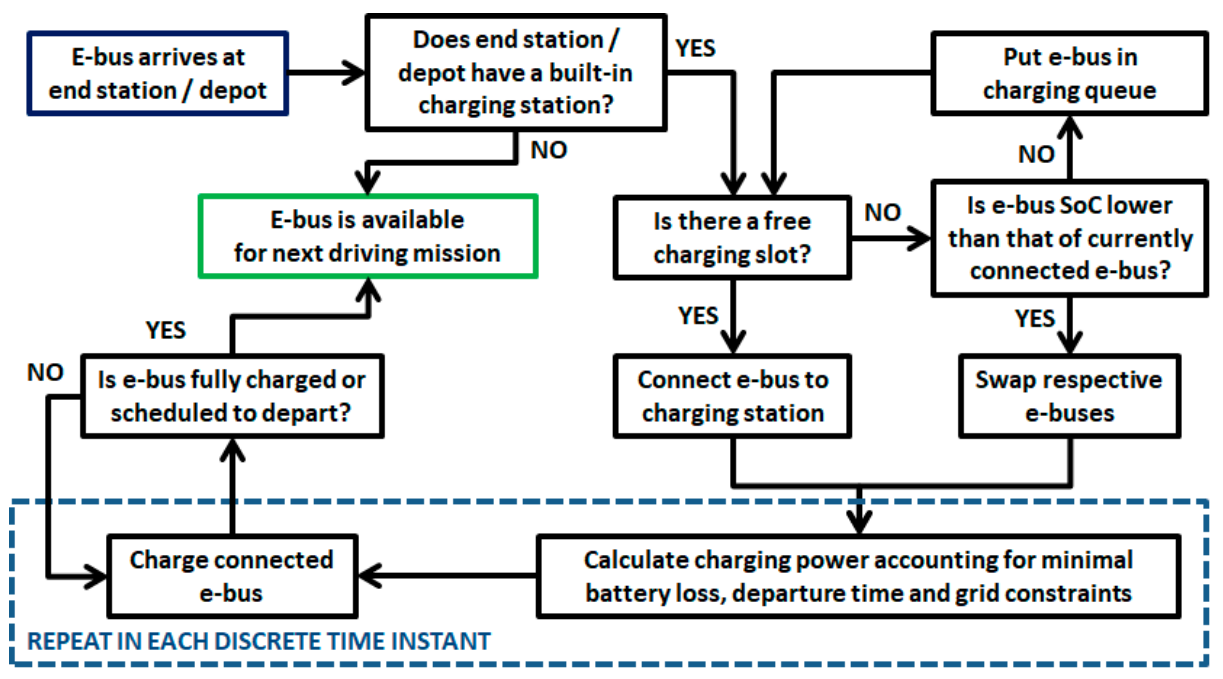

Figure 14. Flowchart of rule-based charging management algorithm (applied to PHEV- and BEV-type buses).

The charging process is managed by taking into account the requirements on satisfying the departure schedule, minimising battery power loss and respecting the grid power constraints. According to [26,27], the battery energy loss is minimised by demanding a linear change of SoC all over the remaining charging interval $\Delta T_{c h}=t_{f}-t_{k}$. Therefore, the SoC rate is updated in each sampling instant $k$ according to:

$$
\frac{d S o C}{d t}=\frac{S o C_{f}-S o C_{k}}{t_{f}-t_{k}}
$$

where $S_{o} C_{k}$ is the current $\mathrm{SoC}$ and $S_{o} C_{f}$ is the target SoC at departure. Inserting Equation (12) into the battery state Equation (1) yields the charging power $P_{b a t t}<0$ to be applied in the $k^{\text {th }}$ sampling instant:

$$
P_{b a t t}=\frac{U_{O C}^{2}\left(S o C_{k}\right)-\left[2 Q_{\max } R_{\text {int }}\left(S o C_{k}\right) \frac{S o C_{f}-S o C_{k}}{t_{f}-t_{k}}+U_{O C}\left(S o C_{k}\right)\right]^{2}}{4 R_{\text {int }}\left(S o C_{k}\right)}
$$

If the charging power $-P_{\text {batt }}$ calculated from Equation (13) is greater/less than the maximum/minimum allowable power (defined by the charger selected), the charging power is limited to the maximum $/ \mathrm{minimum}$ power, respectively. Note that $\Delta T_{c h}=t_{f}-t_{k}$ is saturated in Equation (13) to its lower limit of $30 \mathrm{~s}$ to avoid division by zero. 
Once the charging power profile is obtained for each sampling step $k$ and for $i^{\text {th }}$ vehicle from the total number of $N_{v}$ vehicles connected to chargers at the same grid sections (e.g., depot), it is checked if the total charging power is greater than the maximum grid power $P_{\text {grid,max }}$. If this applies, the charging power is scaled down to satisfy the grid power constraint:

$$
P_{b a t t, k, i, c o r r}=\frac{P_{\text {grid, } \max }}{\sum_{i=1}^{N_{v}} P_{\text {batt }, k, i}} P_{\text {batt }, k, i}, \text { if } \sum_{i=1}^{N_{v}} P_{b a t t, k, i}>P_{\text {grid, } \max .} .
$$

\subsection{Obtaining of Near-Optimal Charging System Configurations}

According to the city bus transport characterisation results from Figure 7, there is a number of end stations with relatively long bus resting durations and potentially high utilization of charger units. Additionally, the end station resting time share approaches that of depot (Figure 5), and there are no other emphasised stop locations. Therefore, fast charging stations and belonging transformer substations can be installed at end stations to provide bus recharging, while otherwise the available power can be utilised to supply city e-mobility hubs built around the end stations. High-power off-board chargers with built-in pantograph are considered (150 or $300 \mathrm{~kW}$, see Table 2) [19]. In addition, the slow-to-modestly fast plug-in charging solutions can be considered for a depot, where the charging time can be long in night (Figure 6).

\subsubsection{PHEV Fleet Case}

Figure 15 shows the PHEV fleet simulation results for different number of end stations equipped with a single fast charger per station $(150 \mathrm{~kW})$ and a five work day period. Charging in depot was not considered because the small-capacity PHEV battery (Table 2) can quickly be recharged at the end stations, where the buses rest for a relatively long time (Figures 6 and 7). The results shown in Figure 15 point out that the fuel consumption saving converges to $-41 \%$ as the number of end station charging spots approaches six. Of course, as the fuel consumption reduces, the electricity consumption grows, but the overall energy cost is reduced by $17 \%$ due to cheaper electricity. By conducting PHEV fleet simulations over the five-month period, it has been found that the optimal number of charging stations should be incremented to seven.

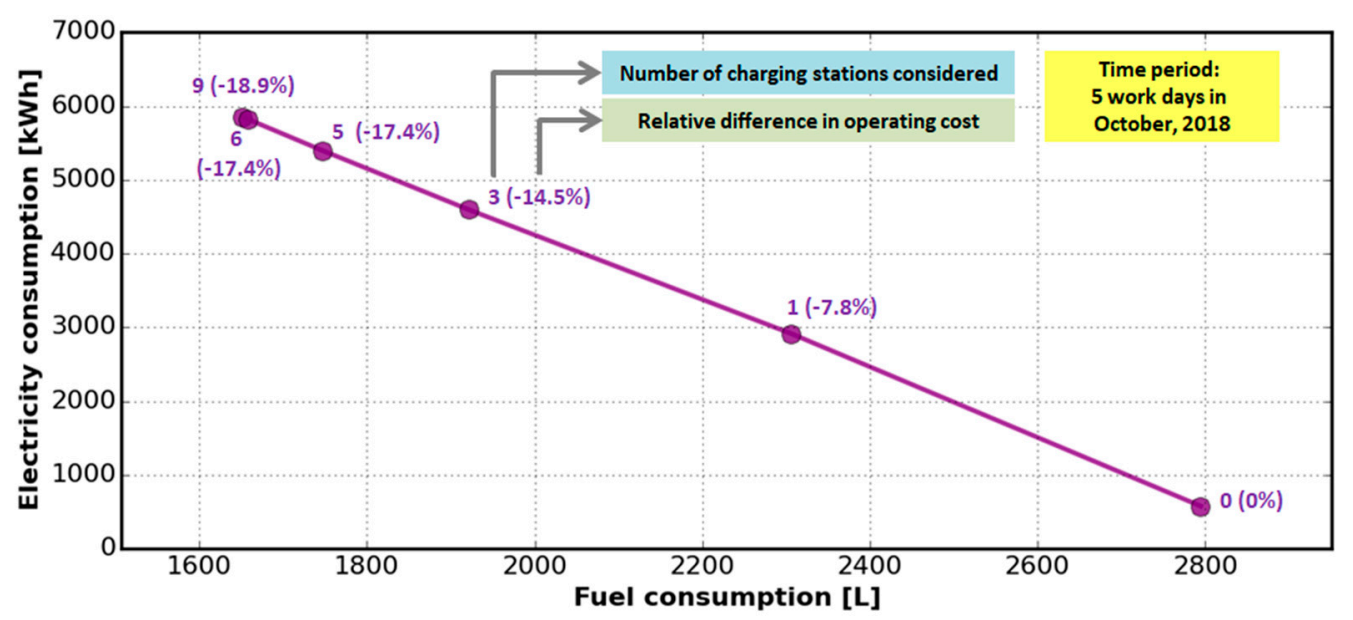

Figure 15. Pareto frontier-like plot showing PHEV bus fleet electricity vs. fuel consumption costs for different number of end stations equipped with a fast charger per station.

\subsubsection{Case of BEV Fleet}

The BEV fleet simulation results are shown in Table 4 . The full five-month period is considered to cover a larger number of "critical" days when reserve buses may be needed. Only scenarios with the number of end-station charging spots being in the vicinity of the optimal one found for the PHEV fleet 
is examined (around six stations plus depot, each considering a single fast charger). The maximum charging power is set to the levels of $150 \mathrm{~kW}$ or $300 \mathrm{~kW}$. Finally, various battery capacities are considered (76, 150 and $250 \mathrm{kWh}$, as the capacities available for the considered bus [19]).

Table 4. BEV fleet simulation results for different number of charging spots (located at end stations and depot) and reserve buses, and different battery capacities (full five-month period).

\begin{tabular}{cccccc}
\hline Case & $\begin{array}{c}\text { Battery } \\
\text { Capacity }\end{array}$ & $\begin{array}{c}\text { Charging Power } \\
\text { (Number of } \\
\text { Charging Stations) }\end{array}$ & $\begin{array}{c}\text { Percentage of Total } \\
\text { Electricity } \\
\text { Consumed by } \\
\text { Reserve Buses }\end{array}$ & $\begin{array}{c}\text { Number of } \\
\text { Reserve Buses } \\
\text { Required }\end{array}$ & $\begin{array}{c}\text { Number of Bus } \\
\text { Swaps Required } \\
\text { (Number of Days } \\
\text { when Swapping } \\
\text { Occurs Out of 152) }\end{array}$ \\
\hline BEV 1 & $76 \mathrm{kWh}$ & $300 \mathrm{~kW}(6)$ & $9.2 \%$ & 2 & $558(106)$ \\
\hline BEV 2 & $76 \mathrm{kWh}$ & $300 \mathrm{~kW}(7)$ & $1.8 \%$ & 2 & $94(54)$ \\
\hline BEV 3 & $76 \mathrm{kWh}$ & $300 \mathrm{~kW}(8)$ & $1.7 \%$ & 2 & $90(52)$ \\
\hline BEV 4 & $150 \mathrm{kWh}$ & $150 \mathrm{~kW}(8)$ & $0.6 \%$ & 2 & $4(3)$ \\
\hline BEV 5 & $250 \mathrm{kWh}$ & $150 \mathrm{~kW}(7)$ & $0.00 \%$ & 0 & $0(0)$ \\
\hline
\end{tabular}

The results shown in Table 4 point out that by increasing the number of charging stations, the percentage of total electricity consumed by reserve buses drops from $9.2 \%$ (case BEV 1) to $1.8 \%$ (case BEV 2). Likewise, the number of bus swaps (concerning reserve bus) drops from 558 in 106 (out of 152) days (BEV 1) to 94 in 54 days (BEV 2). Figure 16 indicates that in the case BEV 2 notable bus swaps occurs only in several days, which are characterised by peak traffic load (typically due to specific needs such as moving tourists from cruising ships to the old city). Similar trends apply to the case of increasing the battery capacity from $76 \mathrm{kWh}$ to $150 \mathrm{kWh}$ and further to $250 \mathrm{kWh}$ (cases BEV 4 and BEV 5, respectively), where the reserve buses are marginally needed in the former case, and not needed in the latter case.

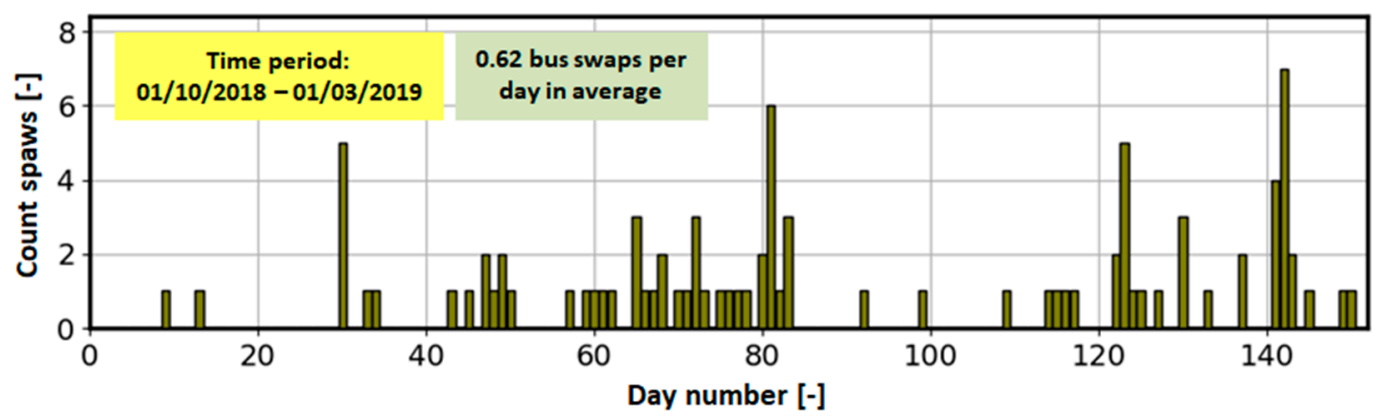

Figure 16. Number of daily bus swaps with reserve buses for BEV 2 case.

Based on the above results, the case BEV 5 might be considered as optimal. However, since increasing of the battery capacity of each bus in a fleet is rather expensive and the need for reserve buses in case BEV 2 is minor (only 1.8\%), the case BEV 2 has been adopted as an optimal for final simulations discussed in Section 5.4.

\subsection{Comparative Energy Consumption Results}

Table 5 gives the energy consumption simulation results for the PHEV and BEV fleets configured in the previous two sections, as well as HEV and CONV fleets, all simulated over the full recording period. The HEV fleet can reduce the fuel consumption by around $50 \%$ compared to CONV fleet, owing to regenerative braking, switching the engine off in low speed conditions and placing the engine operating points in the high-efficiency region (Section 4; see also Table 3). Using the PHEV buses provides additional fuel savings, i.e., the fuel consumption reduction compared to CONV case is around $70 \%$. This is due to the use of electricity coming from grid by means of fast charging at end 
stations. The PHEV fleet electricity consumption equals almost $50 \%$ of what is consumed by BEV fleet, which is owing to a relatively low portion of operation in the CS mode (25.5\%).

Table 5. Fuel and electricity consumption per fleet type for full five-month period.

\begin{tabular}{ccccc}
\hline & \multicolumn{3}{c}{ Fleet Type (Total of 10 Buses) } \\
\cline { 2 - 5 } & CONV & HEV & PHEV & BEV \\
\hline $\begin{array}{c}\text { Fuel } \\
\text { Consumption, L }\end{array}$ & $\mathbf{1 4 5 , 2 9 5 ~ ( * ~ R e f ) ~}$ & $\begin{array}{c}73,625 \\
(-49.3 \%)\end{array}$ & $\begin{array}{c}45,120 \\
(-68.9 \%)\end{array}$ & N/A \\
\hline $\begin{array}{c}\text { Electricity } \\
\text { Consumption, kWh }\end{array}$ & N/A & N/A & $145,054(-45.9 \%)$ & $\mathbf{2 6 8 , 0 3 5 ~ ( * ~ R e f ) ~}$ \\
\hline$*$ Ref stands for referent case, and values in brackets represent relative differences with respect to referent case
\end{tabular}

The COM also calculates the well-to-wheel $\mathrm{CO}_{2}$ emissions taking into account the data on $\mathrm{CO}_{2}$ emissions of power plants, as used in [28] for the cases considering coal, natural gas and renewable energy production. The HEV vs. CONV fleet $\mathrm{CO}_{2}$ emissions reduction is around $50 \%$, while in the cases of PHEV and BEV fleets, the reduction is from 30\% to $65 \%$ and from $30 \%$ to $93 \%$, respectively, where the lower and higher margins correspond to coal and renewable energy production scenarios.

\section{Techno-Economic Analysis Module (TEAM)}

\subsection{General Description and TCO Model}

According to Figure 2, the TEAM uses the simulation data outputted by the COM, as well as the fleet loan payment, insurance, registration, maintenance and similar costs provided by DMM, in order to calculate the fleet TCO (Figure 17). The TCO corresponds to what is in financial terminology called Net Present Value (NPV) of an investment, which is an index that valorises the investment while considering the time value of money. Rates at which the money value decreases or increases over time are in this case modelled by the inflation and discount rates, respectively (where the latter corresponds to the profit that today's money can generate in the future through investments or bank savings). Calculation of future value of money is called compounding, while the opposite approach, in which the NPV of future money is calculated, is referred as discounting. The TCO is calculated by discounting all future expenses, which the investment is expected to generate, to the present time, as shown in Figure 17.

The TCO model components (Figure 17) are divided into three groups depending on the time basis on which the input expenses data are sampled [29], and the corresponding individual costs are given in Table 6 (with no VAT included). The bus service life is considered to be 12 years, the inflation rate 3\% and the discount rate $7 \%$. The annually sampled data include registration, maintenance and insurance (RMI) cost, which have been determined for the CONV fleet based on the (past) data provided by the city bus transport operator, and discounted to prices in 2019 according to inflation data [30]. The RMI cost for the HEV, PHEV and BEV fleets are assumed to be $15 \%, 20 \%$ and $40 \%$ lower, respectively, when compared to the $\mathrm{CONV}$ fleet, because of the significantly reduced $\mathrm{CO}_{2}$ emissions and simplified maintenance of e-buses [31-33].

The monthly expenses relate to loan payment for purchase of new vehicles and charging infrastructure, including the cost of replacing the e-bus batteries. A general-purpose bank loan is assumed, which is taken over a period of seven years, with a continuous interest rate of $5 \%$ and equal monthly annuities. The daily sampled data relate to operating cost, i.e., the fuel and electricity expenses, which are calculated by multiplying fuel and/or electricity consumptions obtained by COM simulations with fuel and/or electricity prices. As in the case of the annually sampled data, the operational cost is adjusted for inflation. Irregular maintenance cost is modelled by a fixed rate occurring every two years. The TEAM also provides the possibility of sensitivity analysis, which allows for the investigation of to what extent variations of a particular parameter affect the TCO. This helps to determine the TCO 
model reliability, e.g., parameters that cause higher TCO sensitivity should be more reliably estimated. The sensitivity analysis is not considered in this paper.

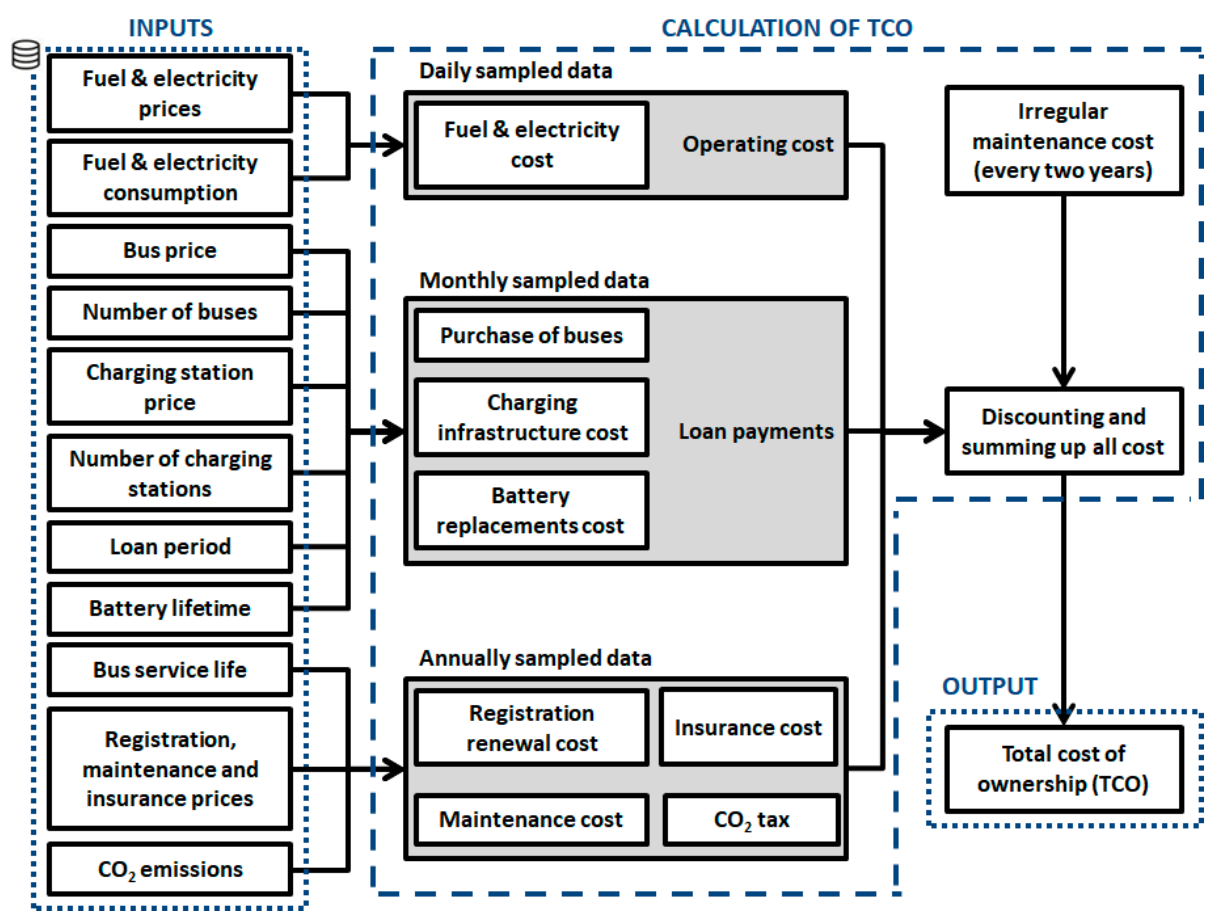

Figure 17. Flowchart of Techno-Economic Analysis Module (TEAM).

Table 6. Input parameters used for TCO calculation for different bus types (no VAT is included).

\begin{tabular}{|c|c|}
\hline \multicolumn{2}{|c|}{ Purchase Cost ${ }^{1}$ of Single Bus (Off-Board Charger) } \\
\hline Conventional (CONV) & 240,000 EUR \\
\hline Hybrid Electric (HEV) & 400,000 EUR \\
\hline Plug-In Hybrid Electric (PHEV) & 420,000 EUR \\
\hline Battery Electric (BEV) & 495,000 EUR \\
\hline \multicolumn{2}{|r|}{ Infrastructural Cost ${ }^{2}$} \\
\hline Fast charging station (150 kW; PHEV case) & 45,000 EUR $($ TS $)+80,000$ EUR $(\mathrm{CS})=125,000$ EUR \\
\hline Fast charging station (300 kW; BEV case) & 45,000 EUR (TS) + 120,000 EUR (CS) = 165,000 EUR \\
\hline \multicolumn{2}{|r|}{ Battery Replacement Cost ${ }^{3}$} \\
\hline Hybrid Electric (HEV), $4.8 \mathrm{kWh}$ & 15,000 EUR \\
\hline Plug-In Hybrid Electric (PHEV), 19 kWh & 25,000 EUR \\
\hline Battery Electric (BEV), $76 \mathrm{kWh}$ & 80,000 EUR \\
\hline \multicolumn{2}{|r|}{ Other Parameters } \\
\hline Bus service life & 12 years \\
\hline Loan period (buses + charging stations) & 7 years \\
\hline Battery lifetime & 6 years \\
\hline Fuel price (mean) & $1.0243 \mathrm{EUR} / \mathrm{L}$ \\
\hline Electricity prices (mean) ${ }^{4}$ & High tariff (HT): 0.1215 EUR/kWhLow tariff (LT): 0.1084 EUR/kWh \\
\hline Inflation / Discount / Loan rates & $7 \%$ \\
\hline $\begin{array}{l}{ }^{1} \text { Includes incentives (1000 EUR for HEV, } \\
{ }^{2} \text { Costs for transformer substation (TS) and } \\
\text { electric utility company and [35], respectiv } \\
\text { replacement is assumed to occur every } 6 \text { ye } \\
7 \text { a.m. to } 9 \text { p.m. (HT), } 9 \text { p.m. to } 7 \text { a.m. (LT) }\end{array}$ & $\begin{array}{l}00 \text { EUR for PHEV and } 5000 \text { EUR for BEV) estimated based on [34]. } \\
\text { larging station (CS) are estimated based on the data provided by local } \\
{ }^{3} \text { The battery replacement costs are estimated based on [35] and the } \\
\text { because the average bus battery life is } 5-12 \text { years [36]. }{ }^{4} \text { Winter time: } \\
\text { aylight saving time: } 8 \text { a.m. to } 10 \text { p.m. (HT), } 10 \text { p.m. to } 8 \text { a.m. (LT). }\end{array}$ \\
\hline
\end{tabular}




\subsection{Simulation Results}

The TCO results are given in Figure 18 for different types of city bus fleets and charging configurations selected in Section 5. Different charging scenarios are considered, starting from optimistic Scenario 1 to conservative Scenario 6. In the basic case (Scenario 1), all the e-bus fleets turn out to be competitive with the CONV fleet, which is explained by the influence of high share of fuel cost (see Figure 19) for the particular case of relatively large fleet utilisation $(250 \mathrm{~km} / \mathrm{bus} /$ day in average; see also Figure 5). For the same reason, the e-bus fleets have relatively comparable TCO values. Similar results are obtained if the fuel and electricity prices are randomly sampled (Scenario 2), rather than being constant as given in Table 6. Scenario 3 accounts for the need to use reserve buses in the case of BEV fleet, as found by COM simulations (Section 5). Since in the considered case, BEV 2, the use of two reserve buses results in a marginal increase of electricity consumption (Table 4 ) and a low number of bus swaps, the use of second reserve bus is very marginal, and is thus excluded from the TCO analysis. Due to the cost of reserve bus, the BEV fleet TCO increases above that of PHEV fleet, but it is still competitive to CONV fleet. When accounting for the e-buses' battery replacement cost (Scenario 4), the TCO of BEV fleet, which has the largest and costliest battery, becomes around $10 \%$ higher than that of CONV fleet. If the PHEV- and BEV-type bus electricity consumption is increased by the factor of $40 \%$ (Scenario 5) or 100\% (Scenario 6) to account for modelling errors (e.g., those related to heating system in winter), the PHEV fleet becomes marginally competitive or uncompetitive, respectively, while the BEV vs. CONV fleet TCO excess tops $23 \%$. This TCO excess in the ultimate BEV case may be compensated for by larger incentives, higher ticket prices (which would reflect better passenger experience), future increase in fuel prices, future decrease of battery prices and similar factors.

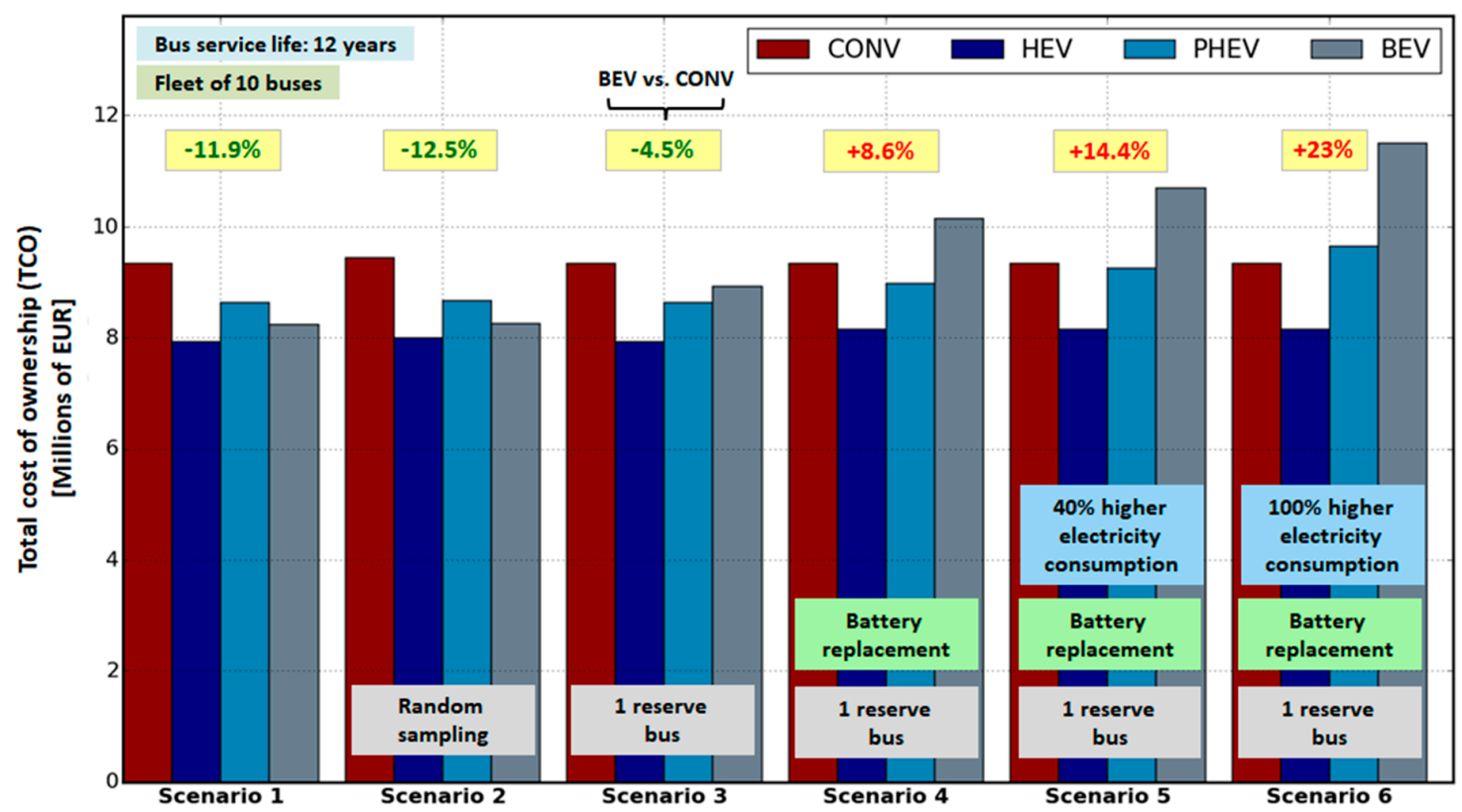

Figure 18. Comparative TCO values for different bus fleet types and electrification scenarios.

The comparative TCO time profiles for different types of bus fleet are shown in Figure 20 for Scenario 4, which is deemed to be most realistic scenario involving the battery replacement and reserve bus cost. The corresponding time profiles of individual TCO costs are shown in Figure 21. For the PHEV, and particularly the BEV fleet, the TCO rapidly rises during the first 7 years due to loan expenses related to the purchase of these expensive buses and corresponding charging infrastructure (Figure 20). Once the loan is paid off, the energy cost becomes dominant, where the efficiency of e-buses and low cost of electricity become beneficial and bring significant savings, as opposed to the CONV case, where the fuel expenses dominate (Figure 21). 


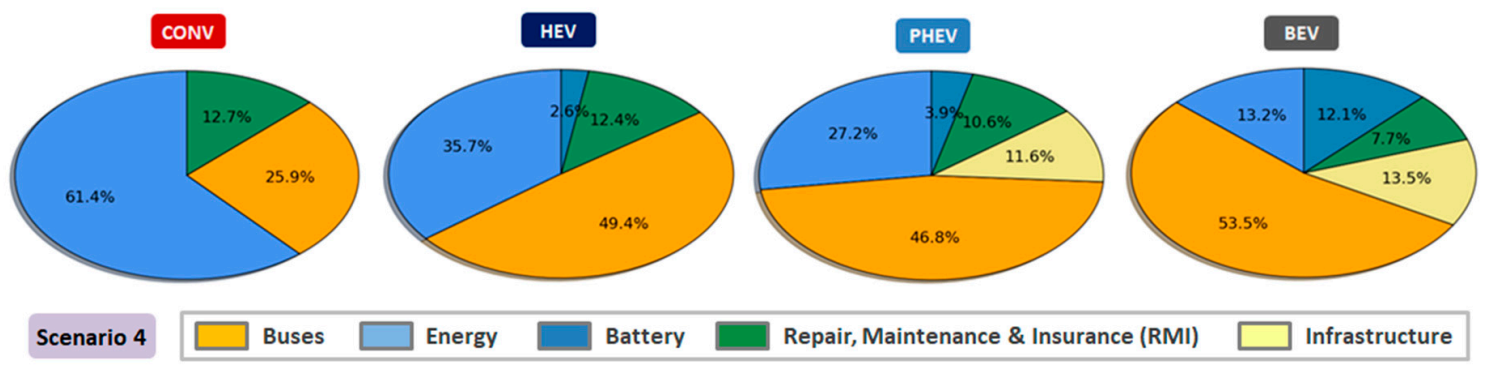

Figure 19. Cost shares for different type of bus fleets and Scenario 4 from Figure 18.

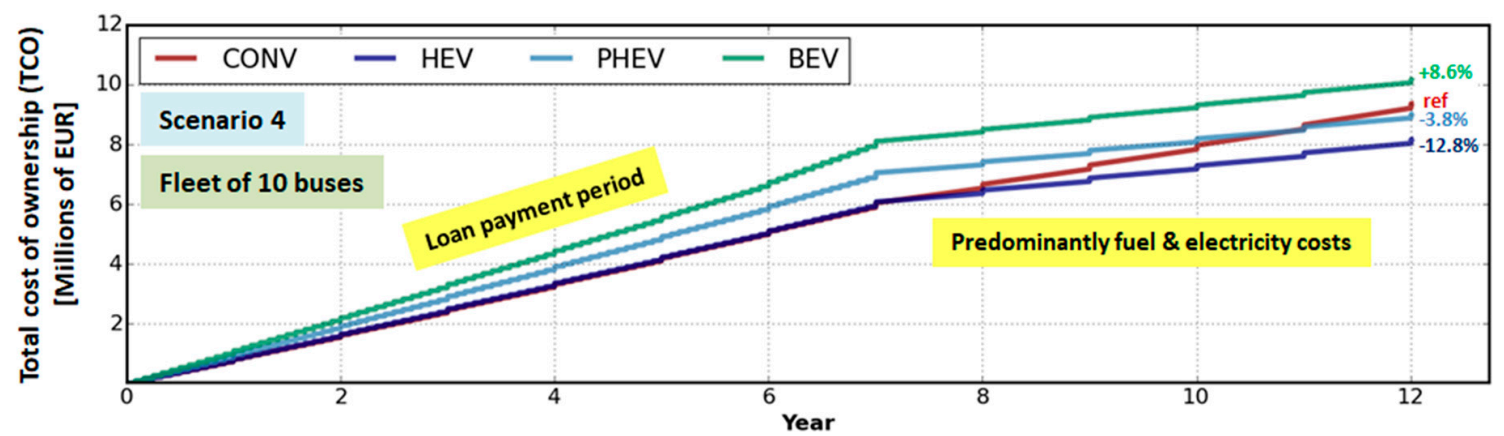

Figure 20. TCO time profile for different bus fleet types and Scenario 4 from Figure 18.
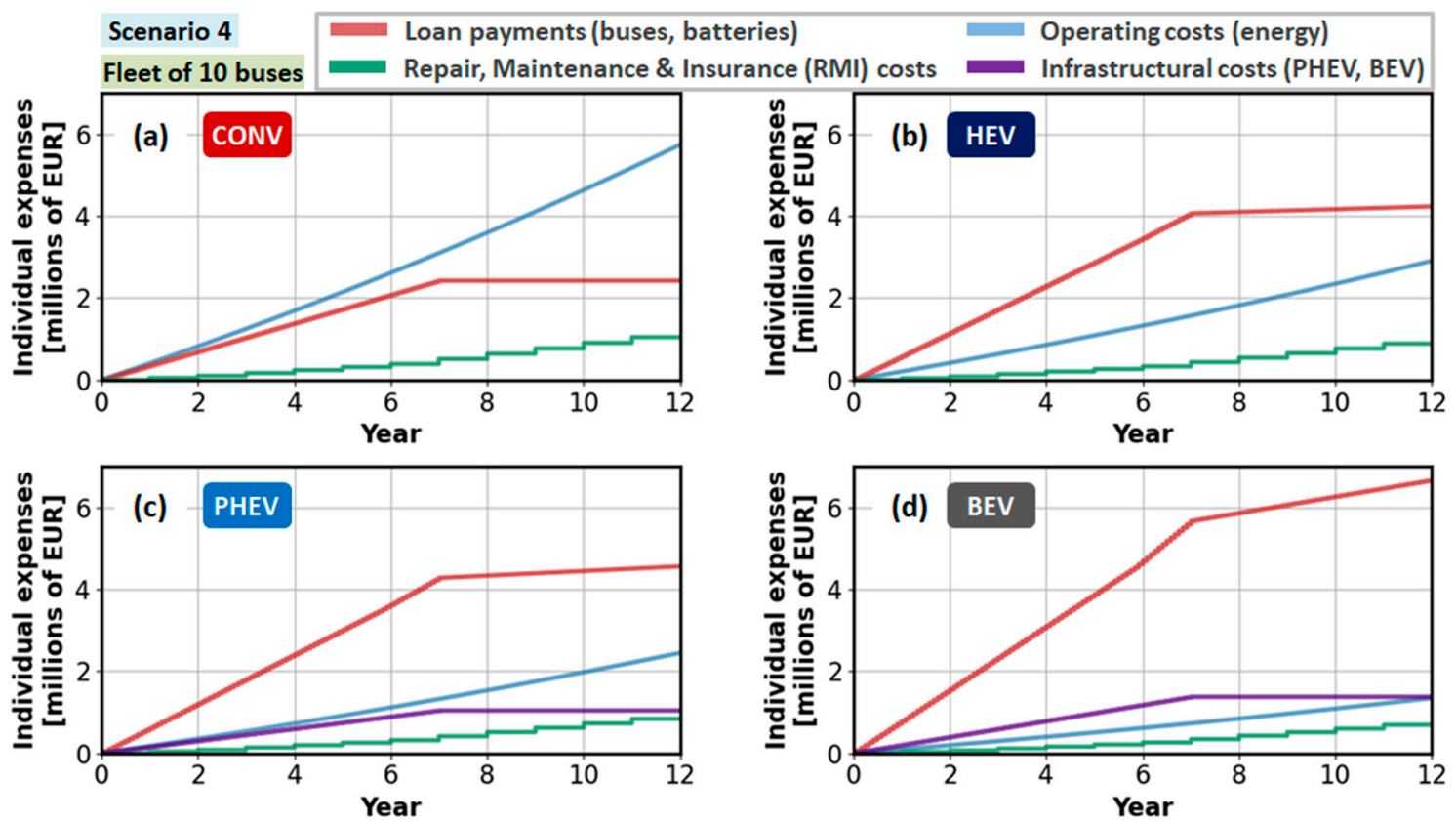

Figure 21. Time profiles of individual TCO costs for different type of bus fleets and Scenario 4 from Figure 18.

Figure 19 shows the percentage shares of individual costs for different types of bus fleets. As the electrification evolves from HEV, via PHEV to BEV buses, the energy (fuel and electricity) cost share monotonically and significantly reduces, but the bus and charging infrastructure cost share increases with similar trends. The PHEV and particularly BEV fleets have lower RMI cost, but this saving is not large enough to compensate for the battery replacement cost. 


\section{Conclusions}

A unique city bus transport electrification tool has been presented, which relies on virtual simulation of conventional and e-bus fleets over recorded driving cycles, including charging management. The tool allows for arbitrary setting of charging station locations, number and parameters of chargers per each station, grid constraints, e-bus battery capacity and similar factors. A special emphasis was on providing a computationally efficient, multiple-maps-based backward looking e-bus model including the vehicle control strategy and heuristic charging management algorithm. In support of electrification planning and decision making, the tool finally provides the total cost of ownership (TCO) of city bus fleets with conventional (CONV) buses and different types of e-buses (HEV, PHEV and $\mathrm{BEV})$. It has been demonstrated through a pilot study related to city bus transport in Dubrovnik, based on which the following main conclusions are drawn.

(1) The considered city bus transport system is such that the city buses are resting in the depot during a relatively short period over the night (typically $3 \mathrm{~h}$ ), while they are dwelling at end stations for rather significant time (from 10 to 20 min per stay). Therefore, fast charging at end stations (and also in depot for BEV-type buses) relying on stationary chargers equipped with pantograph has been found to be a favourable solution.

(2) The use of a specific, map-based structure of the e-bus model allowed for simulating the bus fleets 20,000 times faster than real time, thus, reducing the full-year 10-bus fleet simulation to a couple of hours on a standard computer workstation.

(3) The comparative virtual simulation results have shown that the use of HEV-and PHEV-type city buses results in reduction of fuel consumption of up to $50 \%$ and $70 \%$, respectively, when compared to CONV buses, while BEV buses do not consume fuel at all. The charging system optimisation has shown that the optimal number of end stations equipped with fast chargers is seven (out of 10 ), where a single reserve bus is marginally needed in the BEV case. The BEV battery capacity can be relatively small $(76 \mathrm{kWh})$ due to the effective opportunity charging and relatively short routes.

(4) The TCO analysis has pointed out that the BEV fleet cannot be competitive to CONV fleet (8.6\% higher TCO for BEV vs. CONV), while the HEV fleet is competitive (12.8\% lower TCO vs. $\mathrm{CONV}$ ) and the PHEV fleet is marginally competitive ( $3.8 \%$ lower TCO vs. CONV) in a realistic scenario involving the battery replacement and single reserve bus in the BEV case (Scenario 4). Although the HEV fleet is competitive to the CONV fleet and can reduce the fuel consumption and emissions by up to $50 \%$, it still shares the basic disadvantages of CONV fleet (noisy, no e-drive option in low emission zones, significant emissions).

The future work could be directed to the following tool improvements: (i) optimisation of charging system configuration (e.g., by using genetic algorithm) instead of using the expert knowledge when repeating the virtual simulations for different configurations; (ii) using parallel computing to further increase the numerical efficiency of virtual simulations, particularly when optimisation loop is added; (iii) off-line route rescheduling to avoid or mitigate the use of reserve buses in the BEV case or to redirect the e-buses to designated location for daily recharging; (iv) performing city bus transport electrification analyses using limited set of standard GPS/GPRS tracking data while relying more on the bus schedules; (v) considering other economic models when conducting techno-economic analyses to determine the TCO.

Author Contributions: Conceptualisation, J.T., B.Š. and J.D.; Methodology, J.T., J.S., F.M. and J.D.; Software, J.T., J.S. and F.M.; Validation, J.T., J.S., F.M. and J.D.; Writing-Original Draft Preparation, J.T., J.S., F.M. and J.D.; Writing-Review and Editing, J.D.; Visualisation, J.T., J.S. and F.M.; Supervision, B.Š. and J.D. All authors have read and agreed to the published version of the manuscript.

Funding: It is gratefully acknowledged that this work was supported by the EU European Regional Development Fund trough Interreg CE project SOLEZ ("Smart Solutions supporting Low Emission Zones and other low-carbon mobility policies in EU cities"; https://www.interreg-central.eu/Content.Node/SOLEZ.html). 
Acknowledgments: In addition, the research work of the first author has been supported by the European Regional Development Fund under the grant KK.01.1.1.01.0009 (DATACROSS). The authors' appreciation also goes to the city bus transport company Libertas Dubrovnik d.o.o. and the Dubrovnik Development Agency (DURA) for the data support and effective cooperation.

Conflicts of Interest: The authors declare no conflict of interest.

\section{Abbreviations}

\begin{tabular}{|c|c|c|c|}
\hline AMT & $\begin{array}{l}\text { Automated Manual } \\
\text { Transmission }\end{array}$ & ECMS & Equivalent Consumption Minimisation Strategy \\
\hline AT & Automatic Transmission & EV & Electric Vehicle \\
\hline BEV & Battery Electric Vehicle & GPRS & General Packet Radio Service \\
\hline CAN & Controller Area Network & GPS & Global Positioning System \\
\hline $\mathrm{COM}$ & Charging Optimisation Module & $\mathrm{M} / \mathrm{G}$ & Motor/Generator \\
\hline CONV & Conventional (Diesel) Vehicle & PHEV & Plug-In Hybrid Electric Vehicle \\
\hline CS & Charge Sustaining (mode) & $\mathrm{RB}$ & Rule-Based (controller) \\
\hline CD & Charge Depleting (mode) & RMI & Registration, Maintenance and Insurance \\
\hline DMM & Data Management Module & SoC & State of Charge \\
\hline DPPM & Data Post-Processing Module & TCO & Total Cost of Ownership \\
\hline EBSM & E-Bus Simulation Module & TEAM & Techno-Economic Analysis Module \\
\hline
\end{tabular}

\section{References}

1. Kumar, R.R.; Alok, K. Adoption of electric vehicle: A literature review and prospects for sustainability. J. Clean. Prod. 2020, 253. [CrossRef]

2. Das, H.S.; Rahman, M.M.; Li, S.; Tan, C.W. Electric vehicles standards, charging infrastructure, and impact on grid integration: A technological review. Renew. Sustain. Energy Rev. 2020, 120. [CrossRef]

3. Safoutin, M.J. Predicting the Future Manufacturing Cost of Batteries for Plug-In Vehicles for the U.S. Environmental Protection Agency (EPA) 2017-2025 Light-Duty Greenhouse Gas Standards. World Electr. Veh. J. 2018, 9, 42. [CrossRef]

4. Tiechert, O.; Chang, F.; Ongel, A.; Lienkamp, M. Joint Optimization of Vehicle Battery Pack Capacity and Charging Infrastructure for Electrified Public Bus Systems. IEEE Trans. Transp. Electrif. 2019, 5, 672-682. [CrossRef]

5. Zhang, A.; Kang, J.E.; Kwon, C. Multi-day scenario analysis for battery electric vehicle feasibility assessment and charging infrastructure planning. Transp. Res. Part C 2020, 111, 439-457. [CrossRef]

6. Davidov, S. Optimal charging infrastructure planning based on a charging convenience buffer. Energy 2020, 192. [CrossRef]

7. Gjelaj, M.; Hashemi, S.; Andersen, P.B.; Traehold, C. Optimal infrastructure planning for EV fast-charging stations based on prediction of user behaviour. IET Electr. Syst. Transp. 2020, 10, 1-12. [CrossRef]

8. Perera, P.; Hewage, K.; Sadiq, R. Electric vehicle recharging infrastructure planning and management in urban communities. J. Clean. Prod. 2020, 250. [CrossRef]

9. Cavadas, J.; Homem de Almeida Correia, G.; Gouveia, J. A MIP model for locating slow-charging stations for electric vehicles in urban areas accounting for driver tours. Transp. Res. Part E 2015, 75, 188-201. [CrossRef]

10. Xiao, D.; An, S.; Cai, H.; Wang, J.; Cai, H. An optimization model for electric vehicle charging infrastructure planning considering queuing behaviour with finite queue length. J. Energy Storage 2020, 29.

11. Baouche, F.; Billot, R.; Trigui, R.; El Faouzi. Efficient Allocation of Electric Vehicles Charging Stations: Optimization Model and Application to a Dense Urban Network. IEEE Trans. Intell. Transp. Syst. 2014, 6, 33-43. [CrossRef]

12. Nyman, J.; Olsson, O.; Grauers, A.; Östling, J.; Ohlin, G.; Pettersson, S. A user-friendly method to analyze cost effectiveness of different electric bus systems. In Proceedings of the 30th International Electric Vehicle Symposium \& Exhibition, Stuttgart, Germany, 9-11 October 2017.

13. An, K. Battery electric bus infrastructure planning under demand uncertainty. Transp. Res. Part C 2020, 111, 572-587. [CrossRef]

14. Xylia, M.; Leduc, S.; Patrizio, P.; Kraxner, F.; Silveira, S. Locating charging infrastructure for electric buses in Stockholm. Transp. Res. Part C 2017, 78, 183-200. [CrossRef] 
15. Hoekstra, A.; Vijayashankar, A.; Sundrani, V.L. Modelling the Total Cost of Ownership of Electric Vehicles in the Netherlands. In Proceedings of the 30th International Electric Vehicle Symposium \& Exhibition, Stuttgart, Germany, 9-11 October 2017.

16. Škugor, B.; Hrgetić, M.; Deur, J. GPS Measurement-based Road Grade Reconstruction with Application to Electric Vehicle Simulation and Analysis. In Proceedings of the 10th Conference on Sustainable Development of Energy, Water and Environment Systems, Dubrovnik, Croatia, 27 September-2 October 2015.

17. Soldo, J.; Škugor, B.; Deur, J. Optimal Energy Management and Shift Scheduling Control of a Parallel Plug-in Hybrid Electric Vehicle. In Proceedings of the Powertrain Modelling and Control Conference, Loughborough, UK, 10-11 September 2018.

18. Škugor, B.; Cipek, M.; Deur, J. Control Variables Optimization and Feedback Control Strategy Design for the Blended Operating Mode of an Extended Range Electric Vehicle. SAE Int. J. Altern. Powertrains 2014, 3, 152-162. [CrossRef]

19. Volvo. Available online: https://www.volvobuses.co.uk/ (accessed on 14 May 2020).

20. Guzzella, L.; Sciaretta, A. Vehicle Propulsion Systems, 2nd ed.; Springer: Berlin, Germany, 2007.

21. Bin, Y.; Li, Y.; Feng, N. Nonlinear dynamic battery model with boundary and scanning hysteresis. In Proceedings of the ASME 2009 dynamic systems and control conference, Hollywood, CA, USA, 12-14 October 2009; pp. 245-251.

22. Deur, J.; Asgari, J.; Hrovat, D.; Kovač, P. Modeling and Analysis of Automatic Transmission Engagement Dynamics-Linear Case. J. Dyn. Syst. Meas. Control. 2006, 128, 263-277. [CrossRef]

23. Andersson, C. On Auxiliary Systems in Commercial Vehicles. Doctoral Dissertation, Lund University, Lund, Sweden, November 2004.

24. Škugor, B.; Deur, J.; Cipek, M.; Pavković, D. Design of a Power-split Hybrid Electric Vehicle Control System Utilizing a Rule-based Controller and an Equivalent Consumption Minimization Strategy. Proc. Inst. Mech. Eng. Part D J. Automob. Eng. 2014, 228, 631-648.

25. ZeEUS. Available online: https://zeeus.eu/publications (accessed on 14 May 2020).

26. Soldo, J.; Škugor, B.; Deur, J. Synthesis of Optimal Battery State-of-Charge Trajectory for Blended Regime of Plug-in Hybrid Electric Vehicles in the Presence of Low-Emission Zones and Varying Road Grades. Energies 2019, 12, 4296. [CrossRef]

27. Škugor, B.; Soldo, J.; Deur, J. Analysis of Optimal Battery State-of-Charge Trajectory for Blended Regime of Plug-in Hybrid Electric Vehicle. World Electr. Veh. J. 2019, 10, 75. [CrossRef]

28. Besselink, I.; Oorschot, P.F.; Meinders, E.; Nijmeijer, H. Design of an efficient, low weight battery electric vehicle based on a VW Lupo 3L. In Proceedings of the 25th World Battery, Hybrid and Fuel Cell Electric Vehicle Symposium \& Exhibition, Shenzhen, China, 5-9 November 2010; pp. 32-41.

29. Al-Alawi, B.M.; Bradley, T.H. Total cost of ownership, payback, and consumer preference modeling of plug in HEVs. Appl. Energy 2013, 103, 488-506. [CrossRef]

30. Inflation Calculator. Available online: https://fxtop.com/en/inflation-calculator.php (accessed on 14 May 2020).

31. Aber, J. Electric Bus Analysis for NYC Transit; Columbia University: New York, NY, USA, 2016.

32. Potkany, M.; Hlatka, M.; Debnar, M.; Hanzl, J. Comparison of the Lifecycle Cost Structure of Electric and Diesel Buses. Int. J. Marit. Sci. Technol. 2018, 65, 270-275. [CrossRef]

33. Logtenberg, R.; Pawley, J.; Saxifrage, B. Comparing Fuel and Maintenance Costs of Electric and Gas Powered Vehicles in Canada; $2^{\circ}$ Institute: Sechelt, BC, Canada, 2018.

34. Elin, K. Charging Infrastructure for Electric City Buses. Master's Thesis, KTH Royal Institute of Technology in Stockholm, Stockholm, Sweden, June 2016.

35. Statista. Available online: https://www.statista.com/statistics/883118/global-lithium-ion-battery-pack-costs (accessed on 14 May 2020).

36. Ranta, M.; Anttila, J.; Pihlatie, M.; Hentunen, A. Optimization of opportunity charged bus operation-A case study. In Proceedings of the 32nd International Electric Vehicle Symposium \& Exhibition (EVS32), Lyon, France, 19-22 May 2019.

(C) 2020 by the authors. Licensee MDPI, Basel, Switzerland. This article is an open access article distributed under the terms and conditions of the Creative Commons Attribution (CC BY) license (http://creativecommons.org/licenses/by/4.0/). 